\title{
Design, Synthesis, and Antimicrobial Evaluation of a Novel Bone-Targeting Bisphosphonate-Ciprofloxacin Conjugate for the Treatment of Osteomyelitis Biofilms
}

\author{
Parish P. Sedghizadeh ${ }^{\star}, \dagger, i \mathrm{D}$, Shuting Sun ${ }^{\ddagger}$, Adam F. Junka ${ }^{\S}$, Eric Richard ${ }^{\ddagger}, \|$, Keivan \\ Sadrerafi ${ }^{\ddagger}$, iD , Susan Mahabady ${ }^{\dagger}$, Neema Bakhshalian ${ }^{\dagger}$, Natalia Tjokro ${ }^{\dagger}$, Marzenna \\ Bartoszewicz $§$, Monika Oleksy§, Patrycja Szymczyk ${ }^{\perp}$, Mark W. Lundy ${ }^{\ddagger}$, Jeffrey D. \\ Neighbors $\ddagger, \#$, R. Graham G. Russell ${ }^{\nabla, \bigcirc}$, Charles E. McKenna", and Frank H. Ebetino ${ }^{*}, \ddagger$
}

${ }^{\dagger}$ Center for Biofilms, Ostrow School of Dentistry, University of Southern California, Los Angeles, California 90007, United States "Department of Chemistry, University of Southern California, Los Angeles, California 90007, United States `BioVinc, LLC, Pasadena, California 91107, United States §Department of Pharmaceutical Microbiology and Parasitology, Wrocław Medical University, Wroclaw 50-367, Poland ${ }^{\perp}$ Centre for Advanced Manufacturing Technologies, Wrocław University of Technology, Wrocław 50-370, Poland "Department of Pharmacology and Medicine, Pennsylvania State University College of Medicine, Hershey, Pennsylvania 17033, United States ${ }^{\nabla}$ The Botnar Research Centre, Nuffield Department of Orthopaedics, Rheumatology, and Musculoskeletal Sciences, University of Oxford, Oxford OX3 7LD, United Kingdom ${ }^{\circ}$ The Mellanby Centre for Bone Research, Department of Oncology and Metabolism, University of Sheffield, Sheffield S10 2RX, United Kingdom

\section{Abstract}

Osteomyelitis is a major problem worldwide and is devastating due to the potential for limbthreatening sequelae and mortality. Osteomyelitis pathogens are bone-attached biofilms, making antibiotic delivery challenging. Here we describe a novel osteoadsorptive bisphosphonateciprofloxacin conjugate (BV600022), utilizing a "target and release" chemical strategy, which demonstrated a significantly enhanced therapeutic index versus ciprofloxacin for the treatment of osteomyelitis in vivo. In vitro antimicrobial susceptibility testing of the conjugate against common osteomyelitis pathogens revealed an effective bactericidal profile and sustained release of the parent antibiotic over time. Efficacy and safety were demonstrated in an animal model of

*Corresponding Authors. sedghiza@ usc.edu. Phone: (213) 740-2704. halebetino@ biovinc.com. Phone: (513) 532-4084. ORCID

Parish P. Sedghizadeh: 0000-0003-4190-0497

Keivan Sadrerafi: 0000-0003-3166-7257

ASSOCIATED CONTENT

Supporting Information

The Supporting Information is available free of charge on the ACS Publications website at DOI: 10.1021/acs.jmedchem.6b01615.

Details of NMR, MS, HPLC spectra and elemental analysis data (PDF)

Molecular formula strings (CSV)

The authors declare the following competing financial interest(s): S.S., E.R., K.S., M.W.L., and F.H.E. are paid employees of BioVinc LLC; J.D.N. is a paid consultant of BioVinc LLC; S.S., E.R., M.W.L., F.H.E., and C.E.M. are shareholders of BioVinc LLC. 
periprosthetic osteomyelitis, where a single dose of $10 \mathrm{mg} / \mathrm{kg}(15.6 \mu \mathrm{mol} / \mathrm{kg})$ conjugate reduced the bacterial load by $99 \%$ and demonstrated nearly an order of magnitude greater activity than the parent antibiotic ciprofloxacin $(30 \mathrm{mg} / \mathrm{kg}, 90.6 \mu \mathrm{mol} / \mathrm{kg}$ ) given in multiple doses. Conjugates incorporating a bisphosphonate and an antibiotic for bone-targeted delivery to treat osteomyelitis biofilm pathogens constitute a promising approach to providing high bone-antimicrobial potency while minimizing systemic exposure.

\section{Graphical abstract}

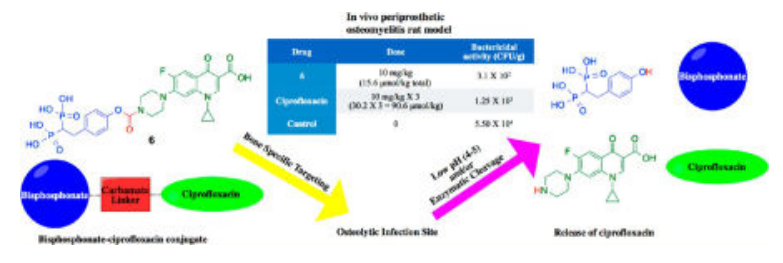

\section{INTRODUCTION}

Infectious bone disease, or osteomyelitis, is a major problem worldwide in human ${ }^{1}$ and veterinary ${ }^{2}$ medicine and can be devastating due to the potential for limb-threatening sequelae ${ }^{3}$ and mortality. ${ }^{4}$ The current approach to treat osteomyelitis is mainly antimicrobial and often intravenous and long-term, with surgical intervention in many cases to control infection. The causative pathogens in the majority of long bone osteomyelitis cases are biofilms of Staphylococcus aureus; these microbes are bound to bone (Figure 1) in contrast to their planktonic (free-floating) counterparts. ${ }^{5}$

The biofilm-mediated nature of osteomyelitis is important in clinical and experimental settings because many biofilm pathogens are uncultivable and exhibit an altered phenotype with respect to growth rate and antimicrobial resistance. ${ }^{5,6}$ The difficulty in eradicating biofilms with conventional antibiotics partly explains why the high success rates of antimicrobial therapy in general have not yet been realized for orthopedic infections, along with the development of resistant biofilm pathogens, poor penetration of antimicrobial agents into bone, and adverse events related to systemic toxicity. ${ }^{3}$

To overcome the many challenges associated with osteomyelitis treatment, ${ }^{7}$ there is increasing interest in drug delivery approaches using bone-targeting conjugates to achieve higher or more sustained local therapeutic concentrations of antibiotic in bone while minimizing systemic exposure. ${ }^{8}$ Conjugation of fluoroquinolone antibiotics to osteoadsorptive bisphosphonates (BPs) (Figure 2) represents a promising approach because of the long clinical track record of safety of each constituent and their advantageous biochemical properties. ${ }^{9,10}$ Ciprofloxacin (Figure 2) has several advantages for repurposing in this context: (1) it can be administered orally or intravenously with relative bioequivalence; (2) it is already FDA approved and indicated for bone and joint infections caused by Pseudomonas aeruginosa and several other pathogens; (3) it has broad spectrum antimicrobial activity that includes the most commonly encountered osteomyelitis pathogens like $S$. aureus, P. aeruginosa for long bone osteomyelitis, ${ }^{11}$ and Aggregatibacter actinomycetemcomitans for jawbone osteomyelitis; ${ }^{12}$ (4) it demonstrates bactericidal 
activity in clinically achievable doses; ${ }^{13}$ and (5) it is the least expensive drug in the fluoroquinolone family. However, like most antibiotics, fluoroquinolones suffer from reduced activity against biofilms as compared to the same bacteria in planktonic forms; this has been shown specifically for ciprofloxacin against $S$. aureus in addition to many other bacterial strains and antibiotic classes. ${ }^{14-17}$ Such studies have demonstrated that biofilms can be one to several orders of magnitude more resistant to the same antimicrobial agents, as compared to their planktonic counterparts. This highlights the importance of a bone-targeted approach for treating osteomyelitis, in order to achieve higher local concentrations of antibiotic against causative biofilms and overcome potential resistance.

The specific bone-targeting properties of the BP family make these drugs ideal carriers for targeting antibiotics to bone in osteomyelitis pharmacotherapy ${ }^{18-20}$ BPs form strong bidentate or tridentate bonds with calcium phosphate mineral, and as a result concentrate in hydroxyapatite (HA), particularly at skeletal sites of active metabolism including sites of infection and inflammation. ${ }^{21}$ BPs also exhibit exceptional stability against both chemical and biological degradation. ${ }^{22} \mathrm{BP}$-fluoroquinolone antimicrobial activity is complex and is related to the specific strain of pathogen tested, the choice of antibiotic and covalently bound BP moiety, the tether length between the two constituents, the bone binding affinity of the $\mathrm{BP}$, the adsorption-desorption equilibria of the BP, and the stability/lability and kinetics of the linkage moiety used for conjugation. ${ }^{18-20}$ Therefore, accumulating evidence suggests that a "target and release" linker strategy (Figure 2) where a conjugate is stable in circulation, but labile at the bone surface, may offer more opportunities for optimization and success in this context. We thus hypothesized that conjugation of ciprofloxacin to a phenyl BP moiety, through metabolically hydrolyzable carbamate linkers, should mitigate the problems seen with antibiotic dosing in osteomyelitis pharmacotherapy. The cleavable carbamate linkage is a key functionality in many drugs designed for target and release in specific tissues ${ }^{23,24}$ and confers pharmacokinetic advantages such as stability in serum and lability at infected bone surfaces in the presence of an acidic and enzymatic environment (e.g., inflammation or infection). ${ }^{25}$

A recent apparent success utilizing a bone-targeting and release strategy is provided by Morioka et al. ${ }^{26}$ who designed an estradiol analog conjugate using a cleavable variant (carbamate) of the more stable amide peptide bond. Several versions of this linkage were attempted before the identification of a pharmacologically active variant (aryl carbamate). Importantly, they demonstrated that a single dose of a similarly linked BP-estradiol conjugate (at a dose nearly 5600 times lower than the total dose of estradiol alone) produced a similar effect on bone to that of the estradiol dosed alone. ${ }^{26}$ The conjugate also provided an even greater therapeutic index, as there were minimal effects systemically and in uterine tissues compared to the estradiol alone. Pharmacokinetic studies completed by Arns et al. ${ }^{27}$ are in agreement with this dramatic enhancement of potency in studies based on a BPprostaglandin with a more labile linker. Other synthetic examples of this approach in the antimicrobial field are reported for the macrolide class; ${ }^{28}$ however, only alkyl carbamates were explored, and the lack of further success suggests that target and release strategies are likely chemical class-dependent (taking into consideration compatibilities of the functional groups of each component) as well as biochemical target dependent, and the design for any particular chemical class must be customized for its use. 
Here, we describe a novel aryl carbamate BP-ciprofloxacin conjugate 6 (BV600022), evaluate its antimicrobial activity in vitro against common osteomyelitis pathogens, and assess its in vivo safety and efficacy in an animal model of peri-prosthetic osteomyelitis. Importantly, the studies presented herein utilize biofilm models and methodology, in addition to planktonic cultures, to provide greater clinical or translational relevance.

\section{RESULTS}

\section{Chemistry}

The overall synthetic route to 6 is shown in Scheme 1, starting from the relatively pharmacologically inert 4-hydroxyphenylethylidene BP (3). The rationale for this BP design was to retain the bone-seeking ability of the BP moiety while suppressing its unneeded antiresorptive activity, minimizing confounding factors to focus on evaluating the antimicrobial effect due to the parent ciprofloxacin compound. BP ligands can also be designed to have antiresorptive functionality (of varying potency) if needed to provide a dual-action effect of bone tissue protection in addition to antimicrobial effects at the anatomic site of infection. We also chose this phenyl BP with consideration of bone binding affinity and tether length, as previous studies have demonstrated that weak binding affinity decreases targeting efficiency. ${ }^{13,14}$ Importantly, we postulated that the use of an aryl carbamate as a linker might offer optimized stability in plasma and adequate release on bone for this biochemical target as compared to previously derived BP-fluoroquinolone conjugates.

Additionally, we synthesized a similar BP-ciprofloxacin conjugate having an amide linkage as opposed to a carbamate linkage as outlined in Scheme 2 as a control conjugate $\mathbf{1 1}$ (BV600026). Previous investigations have indicated that amide conjugates are not able to release the parent antibiotic and are thus less effective in vitro and in vivo, ${ }^{11}$ which we sought to verify in this instance.

\section{Antibacterial Properties of BP-Ciprofloxacin Conjugates}

Minimal Inhibitory Concentration Assays-The antimicrobial activity of both conjugates (6 and 11) and the parent antibiotic ciprofloxacin in standard laboratory planktonic culture systems was evaluated against a panel of $S$. aureus clinical strains associated with bone infections, including methicillin-sensitive $S$. aureus (MSSA) and methicillin-resistant $S$. aureus (MRSA). Following European Committee on Antimicrobial Susceptibility Testing (EUCAST) guidelines, ${ }^{29}$ results from disc diffusion inhibition zone assays revealed diameters ranging from 25 to $40 \mathrm{~mm}$ (mean 31.5, SD \pm 5), and every strain demonstrated antimicrobial susceptibility to the parent antibiotic ciprofloxacin according to EUCAST clinical breakpoints. Minimal inhibitory concentration (MIC) results for $\mathbf{6}$ and $\mathbf{1 1}$ against eight $S$. aureus strains using microdilution methodology are shown in Table 1. MICs for the parent compound ciprofloxacin were determined concurrently for reference (see Table 1) and were found to be consistent with established clinical breakpoints. ${ }^{29}$ Antimicrobial and MIC results for conjugates $\mathbf{6}$ and $\mathbf{1 1}$ in the in vitro experiments were calculated based on the amount of the parent antibiotic to allow molar comparison to ciprofloxacin. 
Hydroxyapatite Binding Assay-Having established the antimicrobial efficacy of $\mathbf{6}$, we next sought to evaluate HA binding ability. We added HA spherules to our microbiological media and then introduced $\mathbf{6}$ at various concentrations similar to those used in the antimicrobial testing. Quantitative spectroscopic analysis of supernatant (without HA spherules) confirmed significant adsorption and retention of the conjugate by HA (Figure 3).

pH Effect in Antimicrobial Susceptibility Testing (AST) on Planktonic S. aureus Strain ATCC-6538-We selected S. aureus strain ATCC-6538 for further investigation because it demonstrated the lowest MIC profile for both ciprofloxacin and 6 (see Table 1) compared to the other strains tested. This ATCC strain is also a well-known and robust biofilm-forming pathogen. Consequently, we could test our conjugates against the most challenging pathogen to limit bias and overestimated results, while also facilitating assessment of antimicrobial activity in biofilm-based and clinically relevant models. Antimicrobial susceptibility testing (AST) on planktonic $S$. aureus strain ATCC-6538 with 6 under both acidic and physiological $\mathrm{pH}$ was performed to assess the effect of $\mathrm{pH}$ on conjugate activity. Quantitative results from standard microdilution methodology indicated that under acidic conditions ( $\mathrm{pH}$ 5), the antimicrobial activity of $\mathbf{6}$ was improved overall as the $\mathrm{MIC}^{50}$ was reached at half the conjugate concentration required to reach $\mathrm{MIC}^{50}$ under physiological conditions (Figure 4). It is important to note that in these results and in results presented later in this paper, the minimum inhibitory concentration terms $\mathrm{MIC}^{50}$ or $\mathrm{MIC}^{90}$ refer to a reduction of $50 \%$ or $90 \%$ of bacterial load, respectively, and the biofilm-related terms of minimum biofilm inhibitory concentrations $\left(\mathrm{MBIC}^{50}\right.$ or $\mathrm{MBIC}^{90}$ ) refer to similar reductions $(50 \%$ or $90 \%)$ but in biofilm bacterial load.

\section{Time-Kill Assays of 6}

Next, kinetic assays were performed with $\mathbf{6}$ according to Clinical Laboratory Standards Institute (CLSI) methods ${ }^{30}$ Results indicated that this conjugate was bactericidal at the previously established MIC for methicillin-susceptible (ATCC-6538) and methicillinresistant (MR4-CIPS) isolates of planktonic $S$. aureus within $1 \mathrm{~h}$ and up to $24 \mathrm{~h}$, preventing $100 \%$ of bacterial growth; these kinetic studies also revealed that at half the MIC value, prevention of bacterial growth became evident after $2 \mathrm{~h}$ and inhibition was at $50 \%$ of control after $24 \mathrm{~h}$ (Figure 5).

Evaluation of Antimicrobial Efficacy of $\mathbf{6}$ against Biofilms-We then tested $\mathbf{6}$ against preformed bacterial biofilms on two different substrates (polystyrene and HA discs) to evaluate antimicrobial efficacy against biofilms and to also determine if substrate bindingspecificity plays any role in the observed antimicrobial efficacy. Biofilms of $S$. aureus (ATCC-6538), and additionally biofilms of $P$. aeruginosa (ATCC-15442), were grown on polystyrene or HA as substrates and were subjected to varying concentrations of $\mathbf{6}$ for assessment of antimicrobial activity. We tested $P$. aeruginosa here because it is a Gramnegative pathogen and the second most common clinical pathogen in osteomyelitis, though less frequent in prevalence than Gram-positive $S$. aureus. Figure 6 shows results for polystyrene as the substrate for biofilm growth, and the minimal biofilm inhibitory concentration $\left(\mathrm{MBIC}^{50}\right.$ ) of $\mathbf{6}$ was $15.6-31.2 \mu \mathrm{g} / \mathrm{mL}$ for $S$. aureus ATCC-6538, which was comparable to the MIC for this strain in planktonic cultures. No MBIC ${ }^{50}$ was observed for $P$. 
aeruginosa ATCC-15442 in the tested range of concentrations, and no $\mathrm{MBIC}^{90}$ was observed for either pathogen.

However, when HA discs were used as the biofilm substrate, marked bactericidal activity was observed with 6. As shown in Figure 7, all tested concentrations of this conjugate resulted in statistically significant ( $p<0.05$, Kruskal-Wallis test) bactericidal activity and reduction of colony forming units (CFUs). The MBIC ${ }^{50}$ of 6 was $16 \mu \mathrm{g} / \mathrm{mL}$, and the MBIC $^{90}$ was $100 \mu \mathrm{g} / \mathrm{mL}$ against $S$. aureus strain ATCC-6538; the MBIC ${ }^{90}$ for the parent drug ciprofloxacin was $8 \mu \mathrm{g} / \mathrm{mL}$ against this pathogen. However, against the $P$. aeruginosa strain ATCC-15442, ciprofloxacin had no inhibitory or bactericidal activity in this setting, while the conjugate was bactericidal in acidic and physiological conditions at $50 \mu \mathrm{g} / \mathrm{mL}$ and showed improved bactericidal activity in physiological conditions as compared to $S$. aureus, where improved antimicrobial activity was observed in acidic conditions.

Preventative Antimicrobial Assays-Next, we performed antimicrobial tests with $\mathbf{6}$ in a preventative type of experimental setting with planktonic and biofilm cultures, which could also have clinical relevance in antibiotic prophylactic scenarios for osteomyelitis pharmacotherapy. Here HA spherules were introduced to varying concentrations of $\mathbf{6}$ and then inoculated with $S$. aureus for $24 \mathrm{~h}$, and quantitative assessments indicated no bacterial growth at concentrations as low as $15.6 \mu \mathrm{g} / \mathrm{mL}$ and up to $250 \mu \mathrm{g} / \mathrm{mL}$ of $\mathbf{6}$, and minimal bacterial growth with strong inhibition at conjugate concentrations ranging from 0.24 to 7.8 $\mu \mathrm{g} / \mathrm{mL}$ as shown in Figure 8.

Next, we tested the amide conjugate (11) for ability to treat the $S$. aureus strain ATCC-6538 biofilms in experimental conditions similar to those used to test the carbamate conjugate 6 . When evaluating the activity of $\mathbf{1 1}$ against established $S$. aureus biofilms grown on HA and HA pretreated with 11 prior to biofilm growth in a preventative experimental setting, antimicrobial activity of $\mathbf{1 1}$ even at higher doses than those used to test $\mathbf{6}$ was insignificant in both cases as shown in Figure 9.

When 6 was tested for the ability to prevent $S$. aureus ATCC-6538 biofilms from forming on pretreated HA, the conjugate showed superior antimicrobial activity as compared the parent antibiotic and in contrast to 11, which showed no significant antimicrobial activity. Table 2 shows results of quantitative biofilm cultures and CFU counts after $24 \mathrm{~h}$ of growth, and at $100 \mu \mathrm{g} / \mathrm{mL}$, the parent drug ciprofloxacin inhibited all biofilm growth, whereas at $10 \mu \mathrm{g} / \mathrm{mL}$, $\mathbf{6}$ inhibited all growth. Since the molecular mass of ciprofloxacin is approximately half that of $\mathbf{6 , 6}$ was 20 times more active in achieving complete bactericidal action as compared to ciprofloxacin alone.

In Vivo Safety and Efficacy-Since $\mathbf{6}$ demonstrated promising activity in vitro, we sought to assess drug safety and efficacy in vivo in an animal model of periprosthetic osteomyelitis. This model is a unique in-house jawbone peri-implant osteomyelitis model that was developed specifically for translational value to study biofilm-mediated disease and host response in vivo. ${ }^{31}$ Because a systemic treatment regimen is utilized, this assay also serves to model any infected bone surface, since the resulting osteolysis involved is key to attracting (targeting) high concentrations of a BP-conjugate, like any high turnover site on 
bone, and to subsequently release the active ciprofloxacin component of the conjugate at this diseased bone surface. Briefly, biofilms of the jawbone osteomyelitis pathogen Aggregatibacter actinomycetemcomitans (Aa; wild-type rough strain D7S-1; serotype a), which is not indigenous to rat normal flora and specific to jawbone infections, were preinoculated on miniature titanium implants at $10^{9} \mathrm{CFU}$. To confirm $\mathrm{Aa}$ sensitivity to the parent drug ciprofloxacin prior to our animal studies, we performed AST and MIC assays as performed for the long bone osteomyelitis pathogens described previously. Disc diffusion inhibition zone assays revealed diameters $>40 \mathrm{~mm}$, and the $\mathrm{MIC}^{90}$ was $2 \mu \mathrm{g} / \mathrm{mL}$, indicating strong susceptibility of this microbe to the parent drug ciprofloxacin. Aa has also been tested previously for susceptibility to a $\mathrm{pH}$-sensitive biotinylated ciprofloxacin prodrug and was found to be sensitive to the parent antibiotic. ${ }^{32}$ As with previous pathogens in this study, we also tested Aa biofilm pathogens grown on HA for sensitivity to 6 and found our conjugate displayed effective antimicrobial activity as shown in Figure 10.

After Aa biofilms are established on implants in vitro, they are surgically transferred to the jawbone of each rat. Animals are anesthetized, the cheeks are retracted, and a transmucosal osteotomy is performed so the implants can be manually inserted into the osteotomy and secured. Two biofilm-inoculated implants are placed in each rat ( $n=12$ rats, 24 implants total) in the palatal bone bilaterally. This model allows standardized and reproducible quantities of viable bacteria to be formed as well-established biofilms on each implant, which we have previously demonstrated persists in vivo for several weeks after placement and causes infection, inflammation, and bone destruction locally. ${ }^{31}$

Once the peri-implant infection was established 1 week post-operatively, the animals were dosed with 6, ciprofloxacin alone as a positive control, and sterile endotoxin-free saline as a negative control at the dosing regimens specified in the Experimental Section. To determine appropriate dosing concentrations, we calculated approximate initial doses for the conjugate based on previous studies and pharmacokinetic data using other target and release strategies also in rodents. ${ }^{26}$ We expected that increasing doses of $0.1,1$, and $10 \mathrm{mg} / \mathrm{kg}$ molar equivalents of $\mathbf{6}$ will allow us to determine antimicrobial activity in 2 test animals per group based on sample size estimations and previous experience with the animal model. ${ }^{32}$ Animals were dosed via intraperitoneal injection under general anesthesia, and all compounds were constituted in sterile physiological injectable saline at appropriate $\mathrm{pH}$. Intraperitoneal injection was used because of the ease of administration in small rodents as compared with other parenteral methods like tail vein injection and because the pharmacokinetics of ciprofloxacin following gastrointestinal administration shows excellent bioavailability; serum drug levels achieved after such administration are slightly less but comparable to those with intravenous dosing with no substantial loss after first pass metabolism. ${ }^{33}$ One week after pharmacotherapy, all animals were sacrificed and en bloc resection of periimplant hard and soft tissues was performed and homogenized for quantitative assessment of microbial load.

All animals tolerated the pharmacotherapy well with no cutaneous injection-site reactions or inflammation. There were no signs of gross tolerability issues during therapy. Treatment efficacy was quantitatively measured in terms of the logarithmic reduction of the amount of viable bacteria (mean $\log _{10} \mathrm{CFU} / \mathrm{gram}$ of tissue) as shown in Figure 11. 
In vivo, the single dose of 6 at $10 \mathrm{mg} / \mathrm{kg}$ showed the highest efficacy with a $2 \log$ reduction in bacterial count ( $99 \%$ bacterial killing) and nearly an order of magnitude greater activity than ciprofloxacin alone given at the same per dose concentration $(\mathrm{mg} / \mathrm{kg})$ but in multiple doses (30 mg/kg total dose). Thus, given the greater molecular weight of $\mathbf{6}(\sim 2 \times$ of ciprofloxacin), the administered single dose of 6 at $10 \mathrm{mg} / \mathrm{kg}$ could deliver roughly $5 \mathrm{mg} / \mathrm{kg}$ of effective ciprofloxacin assuming full release, which is one-sixth of the ciprofloxacin molar dose of the control ciprofloxacin arm (30 mg/kg total). Ciprofloxacin alone in a multiple dosing regimen resulted in a 1 log reduction in bacterial counts $(90 \%$ bacterial killing). Concentrations of 6 at 0.1 and $1 \mathrm{mg} / \mathrm{kg}$ had little effect, suggesting that a minimum dose is necessary for clinical effect and that further chemistry optimization may be possible in this context.

To validate our animal study findings and to provide for greater power and larger sample size for statistical analysis, we conducted a second animal experiment nearly identical to the first except for allocation of dosing regimens. Based on dosing data and antimicrobial results from our first animal study described above, we focused this second animal study on three treatment groups: negative control ( $n=5$ rats), 6 at a single high dose of $10 \mathrm{mg} / \mathrm{kg}(n=5$ rats), and 6 at a multiple low dose regimen of $0.3 \mathrm{mg} / \mathrm{kg} 3 \times /$ week ( $n=2$ rats). Dosing groups of 0.1 and $1 \mathrm{mg} / \mathrm{kg}$ were excluded, as they showed no efficacy previously, and the parent antibiotic alone was also excluded since robust historical data exist for ciprofloxacin efficacy, which we also confirmed in our initial animal study. The multiple dosing regimen was utilized again to ascertain whether the lack of recoverable bacteria could be attributed to treatment effect or experimental and sampling error. All other experimental parameters were identical to the first animal experiment, and each animal had two implants placed as before, allowing for two results per animal and providing sufficient power for statistical analyses as determined by sample size estimations.

All animals again tolerated treatment and pharmacotherapy well, and there were no signs of gross tolerability issues during therapy. Clinically during euthanasia and surgical resection, we observed that the majority of the animals in the control group demonstrated evidence of localized peri-prosthetic inflammation as compared to the majority of the animals in the treatment groups which had non-inflamed peri-implant tissues, and implant retention was 23/24 implants (96\%), which is a high retention rate and provided robust power for subsequent analyses. Quantitative antimicrobial results from this second animal experiment are shown in Figure 12. Single factor ANOVA testing ( $a=0.05$ ), comparing CFUs between treatment groups, resulted in a $p$-value $=0.006$ for significance between groups, and posthoc testing utilizing an unpaired $t$ test $(p=0.0005 ; \mathrm{df}=20)$ and Dunnett's multiple comparisons test $(p<0.05)$ revealed significance for the single high dose of 6 treatment as compared to the control, but not for the multiple low-dose group $(p>0.05)$ when compared to the control or to the single high-dose treatment group.

\section{DISCUSSION}

Targeting antibiotics to bone by conjugation to a BP moiety (via a releasable carbamate linker) is a promising approach for the treatment of osteomyelitis biofilms. Results of AST testing and MIC data presented herein indicate that against planktonic $S$. aureus, 
ciprofloxacin and $\mathbf{6}$ have effective bactericidal activity, and that the conjugation linkage impacts antimicrobial activity of the parent drug as evidenced by the weaker activity of $\mathbf{1 1}$ (Table 1). Higher concentrations of $\mathbf{6}$ were required to reach MIC, which is anticipated since conjugation is a chemical modification that can alter the biochemical interactions of the antibiotic prior to release from the conjugate. As a result, properties of the parent drug, including its pharmacodynamic effect, can be altered by such modification. MIC results for 6 were consistent with previous literature indicating that conjugates in this class can retain the antibacterial activity of the parent compound, although at slightly lower levels. ${ }^{9,10}$

Of interest was the wide distribution of MIC values for both conjugates against tested $S$. aureus strains, as compared to ciprofloxacin alone which demonstrated little variance in antimicrobial efficacy against the same strains (Table 1). There are several possible explanations for these results. Different strains of bacteria within the same species are known to show significant variance in terms of virulence and antimicrobial susceptibility/ resistance to an antibiotic. It is well-established that strain-specific variances exist in antibiotic transport and efflux mechanisms, bacterial cell wall density, enzymatic activity levels, resistance mechanisms, and ability to alter $\mathrm{pH}$ of the environment. ${ }^{34}$ Ciprofloxacin bactericidal activity results from intracellular inhibition of enzymes required for DNA replication - topoisomerase II and IV. ${ }^{35}$ The mechanisms underlying the conjugate antimicrobial activity have not yet been elucidated. It is unclear whether these conjugates are completely cleaved outside the bacterial cell and the antibiotic is then transported inside, or whether the intact conjugate can enter the cell wall and is then cleaved to active drug, or if both scenarios occur significantly; in all cases, a difference between species or strains may occur. Specific microbial biochemistries are likely to play an important role in determining conjugate activities.

It has been established that intact conjugates in this class generally lack significant intrinsic antibacterial activity ${ }^{18,19}$ and that any BP-related antimicrobial effect is negligible; therefore, at least partial release of the parent drug is a prerequisite for significant antimicrobial activity, as observed with $\mathbf{6}$. This is consistent with the low antimicrobial activity of $\mathbf{1 1}$ differing in its more stable amide linkage, which resulted in 2-64x the concentration of the more labile carbamate-linked conjugate 6 to achieve the same antibacterial effect in the assay.

After evaluating the antimicrobial efficacy of $\mathbf{6}$, we sought to assess the bone-binding functionality of the BP moiety and found effective adsorption and retention to HA spherules by the conjugate in a concentration-dependent manner. These results are consistent with previously reported analogs in this class containing BP moieties. ${ }^{13,19}$ We then tested whether the activity of $\mathbf{6}$ would vary in different $\mathrm{pH}$ conditions and found a slightly improved profile in acidic conditions, which may be explained at least partially by the fact that the linker is more labile at $\mathrm{pH} 5$ than at $\mathrm{pH} 7.4$, thus releasing more ciprofloxacin at the lower $\mathrm{pH}$. This could be useful for clinical osteomyelitis applications where biofilm pathogens along with host inflammation and osteoclastogenesis produce an acidic local milieu. Other investigators have suggested, however, that although an acidic $\mathrm{pH}$ brought on by infecting organisms and inflammation could result in some drug release in bone, the efficacy of such a process in providing a significant concentration of the antimicrobial agent 
is doubtful, and that prodrug design, conjugation scheme, and susceptibility to local enzymatic hydrolysis likely have greater impact on linker cleavability and efficacy. ${ }^{26}$ Our findings also support such conclusions.

Investigation of time-kill kinetics for $\mathbf{6}$ demonstrated an efficient rate of bactericidal activity against tested bacteria with sustained bactericidal activity over $24 \mathrm{~h}$, supporting cleavage activity of the parent antibiotic with a steadily sustained release profile over time. The antibiotic release kinetics observed here may be different than those observed with currently used biodegradable and non-biodegradable delivery systems for osteomyelitis therapy, which generally demonstrate an initial high bolus of antibiotic release at the site with a smaller percentage of the remaining antibiotic dissipating over an extended period of time. ${ }^{36,37}$

Importantly, in this study, we present evidence for antimicrobial efficacy of conjugates such as 6 in biofilm-relevant models in vitro and in vivo for osteomyelitis treatment. When osteomyelitis biofilms ( $S$. aureus and $P$. aeruginosa) were grown in vitro on different substrates such as polystyrene or HA and then treated with $\mathbf{6}$, the conjugate was more effective against biofilms in the presence of HA versus polystyrene. This indicates that substrate binding-specificity plays a role in antimicrobial activity in addition to factors like strain of pathogen tested and mode of bacterial growth (planktonic versus biofilm). The fact that 6 was effective against osteomyelitis pathogens on HA, but not effective against the same strains on polystyrene as a substrate, indicates that to effectively treat osteomyelitis biofilms, it is necessary to bind to the substrate (e.g., HA) and release the antibiotic directly underneath or within a biofilm rather than just flow the antibiotic along the biofilm surface (as was the case with the parent antibiotic alone or $\mathbf{6}$ on polystyrene, where no substrate binding occurs and no activity was seen against established surface biofilms). The improved activity of $\mathbf{6}$ found in experimental settings using HA discs in comparison to the setting using polystyrene as a substrate is likely due to the fact that the BP moiety of the conjugate possesses high affinity to HA structures, and therefore bacteria adhering to HA were likely subjected to a relatively higher concentration of the parent antibiotic due to localization of 6 to the disc. Also, cleavage of $\mathbf{6}$ at bone under biofilm bacterial cells may be similar to carbamate cleavage under osteoclast cells as previously shown, ${ }^{22}$ suggesting that the local environment plays a role in this context and further indicating that the environment under bacteria, that also causes osteolysis, has similarities to the environment under osteoclasts on bone, since these environments both seem to be able to cleave the aryl carbamate linkage to release the active ciprofloxacin, probably due to a combination of $\mathrm{pH}$ and enzymatic hydrolysis. Previous work by Arns et al. ${ }^{27}$ with BP (radiolabeled) prostaglandin conjugates suggests that, as with most BPs, ${ }^{38}$ the half-life of the conjugate in the bloodstream is $<15$ $\min$. Thus, in that time, the conjugate is either bound to bone or excreted. This research study also demonstrates that the half-life of release of the active drug (prostaglandin in this case) from the BP on the bone surface, with linkages related to our carbamate, is between 5 and 28 days. We believe our linkage must release closer to the 5 day half-life to achieve the exciting in vivo result reported here. Arns et al. and others ${ }^{27}$ have speculated that the mechanism of cleavage is most likely enzymatic under bone cells. In the presence of bacteria on mineral surfaces, it is also likely to be an enzymatic-based cleavage. As is already noted 
in the manuscript during in vitro antimicrobial studies devoid of osteoclasts, our carbamate based conjugate is active, but our non-cleavable amide-based conjugate is far less active.

We also tested our conjugates in osteomyelitis preventative experiments against $S$. aureus and found that $\mathbf{6}$ was 20 times more active in achieving complete bactericidal action as compared to ciprofloxacin alone (Table 2), whereas any antimicrobial activity of $\mathbf{1 1}$ was not detectable (Figure 9). These findings support an efficient mechanism of cleavage and release over time of the parent antibiotic from $\mathbf{6}$ as compared to 11. Efficient binding to HA and release of the parent antibiotic is requisite for conjugates in this class to demonstrate substantial antimicrobial efficacy comparable or better than the parent antibiotic alone, ${ }^{18-20}$ as we observed with the more labile $\mathbf{6}$ but not with the more stable $\mathbf{1 1}$ even at high doses of exposure, confirming that cleavage is necessary at some point for antimicrobial efficacy.

Finally, we sought to test in vivo safety and efficacy of $\mathbf{6}$ in a jawbone peri-implant osteomyelitis rat model using the model jawbone pathogen Aa. To confirm Aa sensitivity to the parent drug ciprofloxacin prior to our animal studies, we performed in vitro AST and MIC assays as performed for the long bone osteomyelitis pathogens in this study. Aa demonstrated strong susceptibility to the parent drug ciprofloxacin consistent with findings from other investigators. ${ }^{12,32}$ We also tested Aa biofilms grown on HA (similar to $S$. aureus and $P$. aeruginosa) for sensitivity to $\mathbf{6}$ and found our conjugate displayed effective antimicrobial activity (Figure 10). Therefore, we performed two consecutive animal experiments utilizing our peri-implant jawbone osteomyelitis model. In the first in vivo study, a single dose of 6 at $10 \mathrm{mg} / \mathrm{kg}$ showed the highest efficacy with $2 \log$ reduction of CFU or $99 \%$ bacterial killing and nearly an order of magnitude greater activity than ciprofloxacin alone given at the same per dose concentration $(\mathrm{mg} / \mathrm{kg})$ but in multiple doses (Figure 11). Lower concentrations of $\mathbf{6}$ in this experiment were ineffective. To validate these results, we performed a second larger and more statistically powered in vivo experiment focusing on the efficacious dosing regimen $(10 \mathrm{mg} / \mathrm{kg})$ of $\mathbf{6}$ as compared to control and multiple dosing regimens of $\mathbf{6}$. Again we found the greatest CFU reduction and efficacy at the single high dose $(10 \mathrm{mg} / \mathrm{kg})$ of conjugate.

In vivo experiments confirmed the ability of $\mathbf{6}$ at a safe and adequate single dose to target infected peri-implant bone and generate a sufficient concentration of the parent antibiotic for bactericidal activity against established $A a$ biofilms when the activity of the parent antibiotic alone had already diminished. Importantly, since microbial quantification involved an en bloc resected tissue homogenate, even biofilm bacteria within canaliculi of the threedimensional osseous architecture are included for analysis and not just surface pathogens (as the methodology did not involve surface scraping for plating and assessment). This suggests efficacious BP absorption/adsorption to peri-prosthetic bone and antibiotic release as evidenced by the considerable reductions in CFU of biofilm bacteria.

These results along with other studies in this field are also indicating that direct comparisons between these conjugates and their parent compound are somewhat arbitrary, as conjugates have unique pharmacometric parameters and predominantly localize to bone due to the $\mathrm{BP}$ moiety. This is in contrast to the parent antibiotics (the fluoroquinolone class in general) which demonstrate much greater muscle and tendon uptake than bone uptake in humans, ${ }^{39}$ 
and thus correlate with adverse events such as Achilles tendon rupture in susceptible populations. Any future pharmacokinetic modeling and testing for conjugates in this class should include a skeletal compartment of distribution mathematically, which is not generally done with ciprofloxacin and most other antibiotic pharmacokinetic studies. We established the importance of such an approach in human populations for accurately determining bone pharmacokinetics of BP drugs. ${ }^{40}$ Such approaches will provide more accurate and necessary pharmacological data in this context and also inform clinical dosing approaches.

\section{CONCLUSIONS}

In summary, we successfully designed and synthesized a BP-ciprofloxacin conjugate $\mathbf{6}$ utilizing a target and release strategy and systematically evaluated the functionality of each constituent of this compound (as well as the conjugate as a whole) in vitro and in vivo. In vitro antimicrobial investigations of $\mathbf{6}$ tested against common osteomyelitis pathogens revealed a strong bactericidal profile, and safety and efficacy was demonstrated in vivo in an animal model of peri-prosthetic osteomyelitis. An amide variant of the conjugate (11) was also synthesized and tested in vitro and the results confirmed a lack of antimicrobial activity of this non-releasing conjugate variant. When biofilm models were used to test $\mathbf{6}$ in vitro (and in all in vivo studies), the conjugate demonstrated the greatest bactericidal activity in treatment and preventative experiments. For translation to practice, a targeting and release strategy utilizing 6 could prove useful by reducing overall dosing concentrations for patients and improving therapeutic index and also by limiting systemic exposure (e.g., muscle/ tendon) through bone targeting. In essence, because biofilm bacteria inhabit internal and external surfaces of bone three-dimensionally, and BPs also target such bone surfaces, this therapeutic could be considered a biofilm-targeting antibiotic in the context of osteomyelitis or infectious bone disease. Antimicrobial activity of conjugates in this class is associated with many parameters, including the species and strains of pathogens tested, mode of growth (biofilm versus planktonic), substrate for biofilm colonization, $\mathrm{pH}$ of the local milieu, drug concentration, bone binding affinity, linkage scheme, and release kinetics. This class of conjugates using BPs as biochemical vectors for the delivery of antimicrobial agents to bone (where biofilm pathogens reside) should represent an advantageous approach to the treatment of osteomyelitis and provide for improved pharmacokinetics while minimizing systemic exposure or toxicity.

\section{EXPERIMENTAL SECTION}

All manipulations were performed under nitrogen atmosphere unless stated otherwise. Anhydrous ethyl ether, anhydrous tetrahydrofuran, anhydrous citric acid, chloroform, and magnesium sulfate were purchased from EMD. 4-Benzyloxy benzyl alcohol, bromotrimethylsilane, 4-nitrophenyl chloroformate, hydrochloric acid (37\%), anhydrous ethanol, anhydrous $N, N$-dimethylformamide, and thionyl chloride were purchased from Sigma-Aldrich. Sodium sulfate was purchased from Amresco. Sodium hydride (57-63\% oil dispersion), tetraisopropyl methylenediphosphonate, $10 \%$ palladium on activated carbon, 4(bromomethyl)benzoate, lithium hydroxide monohydrate, and Nethyldiisopropylamine were purchased from Alfa Aesar. Ethyl acetate, hexane, and dichloromethane were purchased from VWR. Anhydrous methyl alcohol, trimethylamine, and sodium carbonate were 
purchased from Macron. Hydrogen gas was purchased from Airgas. Ciprofloxacin was purchased from Enzo Life Sciences. Acetonitrile (HPLC grade) was purchased from Spectrum. All reagents were used as received, unless stated otherwise. All solvents were dried using $3 \AA$ molecular sieves $(20 \% \mathrm{~m} / \mathrm{v}) .{ }^{41}$ Silica gel was purchased from Silicycle

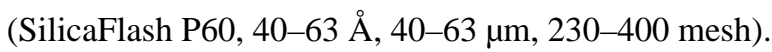

Nuclear magnetic resonance spectra were recorded on Varian 400-MR 2-channel NMR spectrometer with 96-spinner sampler changer and analyzed using TopSpin and MestReNova. Chemical shifts $(\delta, \mathrm{ppm})$ for ${ }^{1} \mathrm{H}$ were referenced to residual solvent peaks. Mass spectra were obtained on a Thermo-Finnigan LCQ Deca XP Max mass spectrometer equipped with an ESI source under positive and/or negative modes using Tune Plus version 2.0 software for data acquisition and Xcalibur 2.0.7 for data processing and reported in $\mathrm{m} / z$. Organic elemental analysis was performed on Flash 2000 elemental analyzer by Thermo Fisher Scientific.

The purities of the final compounds 6 and 11 as well as commercial ciprofloxacin were $\geq 95 \%$ and were determined using ${ }^{1} \mathrm{H},{ }^{31} \mathrm{P}$ NMR spectrometry, HPLC, and elemental analyzer. Analytical HPLC of final compounds were performed on a SHIMADZU HPLC system equipped with diode array detector. LabSolution software was used for both data collection and analysis.

HPLC Method A: Phenomenex Luna $5 \mu$ C18(2) $100 \AA$ analytical column $(250 \times 4.6 \mathrm{~mm})$ operating at a flow rate of $1.0 \mathrm{~mL} / \mathrm{min}$ was used. The following solvent gradient was employed: (Buffer $\mathrm{A}=20 \% \mathrm{ACN}$ in $0.1 \mathrm{M} \mathrm{NH}_{4} \mathrm{OAc}(\mathrm{pH} 7.53$ ), Buffer $\mathrm{B}=70 \% \mathrm{ACN}$ in 0.1 $\mathrm{M} \mathrm{NH}_{4} \mathrm{OAc}(\mathrm{pH} 7.16)$ ) 0-7 min 0\% B, 7-25 $\min 100 \% \mathrm{~B}$, and 25-100 min 100\% B.

\section{Synthesis}

1-(Benzyloxy)-4-(bromomethyl)benzene (1)—4-Benzyloxy benzyl alcohol (1.00 g, $4.67 \mathrm{mmol})$ was dissolved in anhydrous diethyl ether $(25 \mathrm{~mL})$ in an oven-dried flask under nitrogen. The flask was cooled in an ice bath. Bromotrimethylsilane (BTMS) (1.26 mL, 9.52 mmol, 2 equiv) was added by syringe. The flask was allowed to slowly warm to room temperature. After $17 \mathrm{~h}$ of stirring, the reaction mixture was poured into water $(50 \mathrm{~mL})$, and the organic phase was separated. The aqueous phase was washed with diethyl ether $(2 \times 20$ $\mathrm{mL})$, and then the combined organic phase was washed with brine $(2 \times 20 \mathrm{~mL})$ and dried over sodium sulfate. Evaporation of the solvent afforded compound $\mathbf{1}$ as a white crystalline solid (1.23 g, 95\% yield). ${ }^{1} \mathrm{H}$ NMR (400 MHz, chloroform- $d$ ) $\delta 7.47-7.28(\mathrm{~m}, 7 \mathrm{H}), 6.98-$ $6.90(\mathrm{~m}, 2 \mathrm{H}), 5.07$ (s, 2H), 4.50 (s, 2H).

\section{Tetraisopropyl (2-(4-(Benzyloxy)phenyl)ethane-1,1-diyl)bis-(phosphonate) (2)}

-Under nitrogen protection, anhydrous THF $(2 \mathrm{~mL})$ was added to sodium hydride (57-63\% dispersion in mineral oil) $(75 \mathrm{mg}, 1.80 \mathrm{mmol}, 1$ equiv). Tetraisopropyl methylene diphosphonate $(570 \mu \mathrm{L}, 1.80 \mathrm{mmol}, 1$ equiv) was added dropwise with stirring at room temperature. Gas was evolved, and the gray suspended solid was consumed leaving a clear solution. The mixture was stirred a further $10 \mathrm{~min}$. Compound $1(500 \mathrm{mg}, 1.80 \mathrm{mmol}, 1$ equiv) was added in one portion under nitrogen counterflow. The solution remained clear for $1 \mathrm{~min}$ and then became turbid. Stirring was maintained for $2 \mathrm{~h}$, and the reaction progress was 
monitored by TLC (100\% EtOAc visualized by UV and cerium ammonium molybdate (CAM) stain). The reaction mixture was poured into $5 \%$ aqueous citric acid $(30 \mathrm{~mL})$ and extracted with ether $(2 \times 30 \mathrm{~mL})$, washed with brine $(30 \mathrm{~mL})$, and evaporated. The residue was purified by flash chromatography using a EtOAc:Hexane gradient (10-100\%) to afford 2 as a colorless oil ( $0.508 \mathrm{~g}, 52 \%$ yield). ${ }^{1} \mathrm{H}$ NMR (400 MHz, chloroform- $d$ ) $\delta 7.44-7.27$ $(\mathrm{m}, 5 \mathrm{H}), 7.18(\mathrm{~d}, J=8.6 \mathrm{~Hz}, 2 \mathrm{H}), 6.87(\mathrm{~d}, J=8.7 \mathrm{~Hz}, 2 \mathrm{H}), 5.04(\mathrm{~s}, 2 \mathrm{H}), 4.86-4.63(\mathrm{~m}, 4 \mathrm{H})$, $3.15(\mathrm{td}, J=16.6,6.1 \mathrm{~Hz}, 2 \mathrm{H}), 2.44(\mathrm{tt}, J=24.2,6.1 \mathrm{~Hz}, 1 \mathrm{H}), 1.48-1.01(\mathrm{~m}, 24 \mathrm{H}) .{ }^{31} \mathrm{P}$ NMR (162 MHz, chloroform- $d$ ) $\delta 21.11$.

Tetraisopropyl (2-(4-Hydroxyphenyl)ethane-1,1-diyl)bis-(phosphonate) (3)Compound 2 (0.508 g, $0.925 \mathrm{mmol})$ was dissolved in $13 \mathrm{~mL}$ of methanol, and $10 \%$ palladium on activated carbon $(70 \mathrm{mg}, 0.066 \mathrm{mmol}, 0.07$ equiv) was added. The flask was flushed with nitrogen, then hydrogen, and stirred overnight with a hydrogen balloon in place. The reaction mixture was filtered through Celite with $100 \mathrm{~mL}$ of methanol. Evaporation of the filtrate gave the desired compound $\mathbf{3}$ as a slightly yellow oil $(0.368 \mathrm{~g}$, $88 \%$ yield) that was used without further purification. ${ }^{1} \mathrm{H}$ NMR $(400 \mathrm{MHz}$, chloroform- $d$ ) $\delta$ 7.07 (d, $J=8.2 \mathrm{~Hz}, 2 \mathrm{H}), 6.69$ (d, $J=8.2 \mathrm{~Hz}, 2 \mathrm{H}), 4.71(\mathrm{~m}, 4 \mathrm{H}), 3.11$ (td, $J=16.9,6.0 \mathrm{~Hz}$, $2 \mathrm{H}), 2.47$ (tt, $J=24.4,6.0 \mathrm{~Hz}, 1 \mathrm{H}), 1.32-1.21(\mathrm{~m}, 24 \mathrm{H}) .{ }^{31} \mathrm{P}$ NMR (162 MHz, chloroformd) $\delta 21.06$.

\section{4-(2,2-Bis(diisopropoxyphosphoryl)ethyl)phenyl(4-nitrophenyl) Carbonate (4)}

-Compound 3 (7.91 g, $15.9 \mathrm{mmol}$ ) was dissolved in $150 \mathrm{~mL}$ of dichloromethane, and then triethylamine $(6.70 \mathrm{~mL}, 47.9 \mathrm{mmol}, 3$ equiv) was added followed by $p$-nitrophenyl chloroformate ( $3.54 \mathrm{~g}, 17.6 \mathrm{mmol}, 1.1$ equiv) in one portion. Reaction mixture was stirred for $2.5 \mathrm{~h}$ while being monitored with TLC (5\% MeOH in EtOAc, UV visualization). After disappearance of starting material, the reaction was stopped, and the target compound was purified by flash chromatography (1:1 ethyl acetate:hexane) to afford compound 4 ( $4.33 \mathrm{~g}$, $44 \%$ yield). ${ }^{1} \mathrm{H}$ NMR (400 MHz, chloroform- $d$ ) $\delta 8.29$ (d, $\left.J=9.1 \mathrm{~Hz}, 2 \mathrm{H}\right), 7.46$ (d, $J=9.1$ $\mathrm{Hz}, 2 \mathrm{H}), 7.33$ (d, $J=8.5 \mathrm{~Hz}, 2 \mathrm{H}), 7.15(\mathrm{~d}, J=8.6 \mathrm{~Hz}, 2 \mathrm{H}), 4.84-4.58$ (m, 4H), 3.22 (td, $J=$ $16.5,6.2 \mathrm{~Hz}, 2 \mathrm{H}), 2.47$ (tt, $J=24.1,6.2 \mathrm{~Hz}, 1 \mathrm{H}), 1.33-1.14$ (m, 24H).

7-(4-((4-(2,2-Bis(diisopropoxyphosphoryl)ethyl)phenoxy)-carbonyl)piperazin-1yl)-1-cyclopropyl-6-fluoro-4-oxo-1,4-dihydroquinoline-3-carboxylic Acid (5)Ciprofloxacin ( $2.76 \mathrm{~g}, 8.34 \mathrm{mmol}, 1.2$ equiv) was suspended in $74.7 \mathrm{~mL}$ of water in a flask. Then $8.30 \mathrm{~mL}$ of $1 \mathrm{M} \mathrm{HCl}$ was added, and the flask was stirred to dissolve ciprofloxacin, giving a clear colorless solution. $\mathrm{Na}_{2} \mathrm{CO}_{3}$ was added to adjust the $\mathrm{pH}$ to 8.5 , and a thick white precipitate formed. The flask was placed in an ice bath, and compound $4(4.28 \mathrm{~g}, 6.95$ mmol, 1 equiv) dissolved in $83 \mathrm{~mL}$ of THF was added slowly over about $5 \mathrm{~min}$. The flask was then removed from the ice bath, protected from light, and stirred overnight at room temperature. The reaction mixture was concentrated under vacuum to approximately half the original volume and filtered through a fine glass frit funnel. The retained solid was washed with water until no yellow color remained. The solids were then dissolved and washed from the frit with DCM, and the solution was loaded onto a flash silica column and eluted with MeOH:DCM gradient (2-5\%) to afford compound 5 (3.47 g, 51.5\% yield) as a white solid. ${ }^{1} \mathrm{H}$ NMR $\left(400 \mathrm{MHz}\right.$, methanol- $\left.d_{4}\right) \delta 8.79(\mathrm{~s}, 1 \mathrm{H}), 7.93(\mathrm{~d}, J=13.3 \mathrm{~Hz}, 1 \mathrm{H}), 7.54(\mathrm{~s}, 1 \mathrm{H})$, 
$7.30(\mathrm{~d}, J=8.4 \mathrm{~Hz}, 2 \mathrm{H}), 7.05(\mathrm{~d}, J=8.5 \mathrm{~Hz}, 2 \mathrm{H}), 4.70(\mathrm{dpd}, J=7.4,6.2,1.3 \mathrm{~Hz}, 4 \mathrm{H}), 3.90$ (m, 4H), 3.65 (s, br, 1H), 3.39 (s, br, 4H), 3.18 (td, $J=16.6,6.4 \mathrm{~Hz}, 2 \mathrm{H}), 2.65$ (tt, $J=24.3$, $6.3 \mathrm{~Hz}, 1 \mathrm{H}), 1.43-1.34(\mathrm{~m}, 2 \mathrm{H}), 1.34-1.19(\mathrm{~m}, 24 \mathrm{H}), 1.18-1.10(\mathrm{~m}, 2 \mathrm{H}) .{ }^{31} \mathrm{P}$ NMR $(162$ $\mathrm{MHz}$, methanol- $\left.d_{4}\right) \delta 20.71$. MS (ESI +$) \mathrm{m} / z .808 .2(\mathrm{M}+\mathrm{H}), 830.2(\mathrm{M}+\mathrm{Na})$ calcd for $\mathrm{C}_{38} \mathrm{H}_{53} \mathrm{FN}_{3} \mathrm{O}_{11} \mathrm{P}_{2}^{+}$: 808.3.

1-Cyclopropyl-7-(4-((4-(2,2-diphosphonoethyl)phenoxy)-carbonyl)piperazin-1yl)-6-fluoro-4-oxo-1,4-dihydroquinoline-3-carboxylic Acid (6).42,43_Compound 5 $(10.0 \mathrm{mg}, 1.24 \mu \mathrm{mol})$ was dissolved in DCM $(200 \mu \mathrm{L})$ in a $1.5 \mathrm{~mL}$ glass vial, BTMS (200 $\mu \mathrm{L}, 1.52 \mathrm{mmol}, 122$ equiv) was added, and the vial was quickly capped and immersed in a $35^{\circ} \mathrm{C}$ oil bath. After stirring for $24 \mathrm{~h}$, solvent and BTMS were removed under vacuum, 1 $\mathrm{mL}$ of $\mathrm{MeOH}$ was added, and the vial stirred overnight. Solvent was removed under vacuum to afford pure compound $\mathbf{6}$ as a pale yellow solid with green fluorescence $(6.82 \mathrm{mg}, 86.1 \%$ yield). ${ }^{1} \mathrm{H}$ NMR (400 MHz, deuterium oxide) $\delta 8.51(\mathrm{~s}, 1 \mathrm{H}), 7.92(\mathrm{~d}, J=12.2 \mathrm{~Hz}, 1 \mathrm{H}), 7.67$ (s, 1H), $7.47(\mathrm{~d}, J=8.3 \mathrm{~Hz}, 2 \mathrm{H}), 7.10(\mathrm{~d}, J=8.3 \mathrm{~Hz}, 2 \mathrm{H}), 3.98(\mathrm{~s}, 2 \mathrm{H}), 3.79(\mathrm{~s}, 2 \mathrm{H}), 3.67$ (s, $1 \mathrm{H}), 3.42(\mathrm{~s}, 4 \mathrm{H}), 3.16$ (td, $J=15.5,6.8 \mathrm{~Hz}, 2 \mathrm{H}), 2.21$ (tt, $J=6.9,21.6 \mathrm{~Hz}, 1 \mathrm{H}), 1.37$ (d, $J=$ $6.9 \mathrm{~Hz}, 2 \mathrm{H}), 1.15$ (s, 2H). ${ }^{31} \mathrm{P}$ NMR (162 MHz, deuterium oxide) $\delta 19.16 \mathrm{MS}$ (ESI-) $\mathrm{m} / z$. $638.06(\mathrm{M}-\mathrm{H})$ calcd for $\mathrm{C}_{26} \mathrm{H}_{27} \mathrm{FN}_{3} \mathrm{O}_{11} \mathrm{P}_{2}^{-}:$638.1. HPLC (Method A, UV 190, 274, 330 $\mathrm{nm}): t_{\mathrm{r}}=11.62 \mathrm{~min}$.

Methyl 4-(2,2-bis(diisopropoxyphosphoryl)ethyl)benzoate (7). ${ }^{44}$-Under nitrogen atmosphere, in a $25 \mathrm{~mL}$ round-bottom flask, THF $(5 \mathrm{~mL})$ was added to $57-63 \%$ dispersion of sodium hydride in mineral oil ( $0.163 \mathrm{~g}, 4.07 \mathrm{mmol}, 1.4$ equiv). The suspension was cooled to $0{ }^{\circ} \mathrm{C}$, while stirring, and tetraisopropyl methylenediphosphonate $(0.926 \mathrm{~mL}, 2.90$ mmol, 1 equiv) was added gradually. The reaction was allowed to reach ambient temperature, and once hydrogen gas stopped bubbling out of the reaction mixture, the solution was cooled to $0{ }^{\circ} \mathrm{C}$ again. Methyl 4-(bromomethyl)benzoate $(0.465 \mathrm{~g}, 2.03 \mathrm{mmol}$, 0.7 equiv) was dissolved in THF ( $2 \mathrm{~mL})$ and added to the reaction dropwise. The resulting solution was stirred overnight while slowly reaching ambient temperature. The reaction mixture was then cooled to $0{ }^{\circ} \mathrm{C}$ and quenched with $\mathrm{EtOH}(1 \mathrm{~mL})$. A 5\% aqueous solution of citric acid in water $(30 \mathrm{~mL})$ was added, and the mixture was extracted with $\mathrm{Et}_{2} \mathrm{O}(3 \times 30$ $\mathrm{mL}$ ). The combined organics were washed with brine $(50 \mathrm{~mL})$, dried on $\mathrm{Na}_{2} \mathrm{SO}_{4}$, filtered, concentrated under reduced pressure, and purified by silica gel column chromatography using a EtOAc:Hex gradient (10-100\%) to afford 7 as a faint yellow oil $(0.371 \mathrm{~g}, 37.0 \%$ yield). ${ }^{1} \mathrm{H}$ NMR (400 MHz, chloroform- $d$ ) $\delta 7.93(\mathrm{~d}, J=8.0 \mathrm{~Hz}, 2 \mathrm{H}), 7.33(\mathrm{~d}, J=8.4,2 \mathrm{H})$, 4.79-4.68 (m, 4H), 3.88 (s, 3H), 3.24 (td, $J=16.0,6.4 \mathrm{~Hz}, 2 \mathrm{H}$ ), 2.50 (tt, $J=24.0,6.2 \mathrm{~Hz}$, 1H), 1.34- 1.24 (m, 24H). ${ }^{31} \mathrm{P}$ NMR (162 MHz, chloroform- $d$ ) $\delta 20.57$.

4-(2,2-Bis(diisopropoxyphosphoryl)ethyl)benzoic Acid (8) ${ }^{44}$-To a solution of $\mathbf{7}$ $(0.131 \mathrm{~g}, 0.278 \mathrm{mmol})$ in $\mathrm{MeOH}(1.5 \mathrm{~mL})$ in a 8 dram glass vial, $\mathrm{LiOH} \cdot \mathrm{H}_{2} \mathrm{O}(0.058 \mathrm{~g}, 1.39$ $\mathrm{mmol}, 5$ equiv) was added, and the resulting solution was stirred at room temperature overnight. The reaction mixture was evaporated to dryness, the residue was dissolved in water $(30 \mathrm{~mL})$, and $\mathrm{HCl}_{(\mathrm{aq})}(1 \mathrm{M})$ was added slowly to reach $\mathrm{pH} 3$. The resulting mixture was extracted with $\mathrm{CHCl}_{3}(3 \times 30 \mathrm{~mL})$. Combined organics were dried on $\mathrm{MgSO}_{4}$ and concentrated under reduced pressure to afford $\mathbf{8}$ as a thick clear oil $(0.115 \mathrm{~g}, 90.6 \%$ yield $)$. 
${ }^{1} \mathrm{H}$ NMR (400 MHz, chloroform- $d$ ): $\delta=7.96(\mathrm{~d}, J=8.0,2 \mathrm{H}), 7.37(\mathrm{~d}, J=8.0,2 \mathrm{H})$, $4.82-4.74(\mathrm{~m}, 4 \mathrm{H}), 3.28(\mathrm{td}, J=16.6,6.1,2 \mathrm{H}), 2.60(\mathrm{tt}, J=24.2,6.2,1 \mathrm{H}), 1.33-1.26(\mathrm{~m}$, 24H). ${ }^{31} \mathrm{P}$ NMR (162 MHz, chloroform- $d$ ) $\delta 20.57$.

Tetraisopropyl(2-(4-(chlorocarbonyl)phenyl)ethane-1,1-diyl)bis-(phosphonate) (9)-Under nitrogen atmosphere, compound $8(0.162 \mathrm{~g}, 0.339 \mathrm{mmol})$ was dissolved in chloroform $(1 \mathrm{~mL})$, and a catalytic amount of DMF $(1.30 \mu \mathrm{L}, 0.017 \mathrm{mmol}, 0.05$ equiv) was added. Thionyl chloride ( $49.2 \mu \mathrm{L}, 0.678 \mathrm{mmol}, 2$ equiv) was added slowly, and the reaction was allowed to stir for $2 \mathrm{~h}$ at room temperature. Solvents were removed under vacuum to afford 9 as clear oil. The product was immediately used in the next step without further manipulation (quantitative yield).

\section{7-(4-(4-(2,2-Bis(diisopropoxyphosphoryl)ethyl)benzoyl)piperazin-1-yl)-1- cyclopropyl-6-fluoro-4-oxo-1,4-dihydroquinoline-3-carboxylate (10)-}

Ciprofloxacin (0.112 g, 0.339 mmol, 1 equiv) was suspended in chloroform ( $1 \mathrm{~mL})$, and $N, N$-diisopropylethylamine (DIPEA) $(354 \mu \mathrm{L}, 2.03 \mathrm{mmol}, 6$ equiv) was added. Freshly made compound 9 (168 mg, $0.338 \mathrm{mmol}, 1$ equiv) was dissolved in chloroform ( $1 \mathrm{~mL}$ ) and gradually added to the ciprofloxacin:DIPEA suspension. The reaction mixture was covered with foil and stirred at room temperature overnight. The following day, solvents were removed under vacuum, and the resulting crude was dissolved in DCM $(5 \mathrm{~mL})$, filtered through a medium grade frit funnel, and washed with more DCM $(3 \times 5 \mathrm{~mL})$. The filtrate was concentrated under vacuum and further purified by silica gel column chromatography using a MeOH:DCM gradient (0-10\%) to afford $\mathbf{1 0}$ as a viscous oil that gradually solidified ( $0.226 \mathrm{~g}, 65.1 \%$ yield, 1.8 equiv DIPEA salt). ${ }^{1} \mathrm{H}$ NMR (400 MHz, chloroform- $d$ ) $\delta=8.79$ (s, $1 \mathrm{H}), 8.06(\mathrm{~d}, J=12.8,1 \mathrm{H}), 7.38(\mathrm{~m}, 5 \mathrm{H}), 4.80-4.73(\mathrm{~m}, 4 \mathrm{H}), 4.00(\mathrm{~s}, \mathrm{br}, 4 \mathrm{H}), 3.56-3.53$ $(\mathrm{m}, 1 \mathrm{H}), 3.33-3.20(\mathrm{~m}, 6 \mathrm{H}) 2.50(\mathrm{~m}, 1 \mathrm{H}), 1.45-1.38(\mathrm{~m}, 2 \mathrm{H}), 1.32-1.25(\mathrm{~m}, 24 \mathrm{H})$, 1.23-1.19 (m, 2H). ${ }^{31} \mathrm{P}$ NMR (162 MHz, chloroform- $d$ ) $\delta 20.77$.

\section{1-Cyclopropyl-7-(4-(4-(2,2-diphosphonoethyl)benzoyl)piperazin-1-yl)-6-}

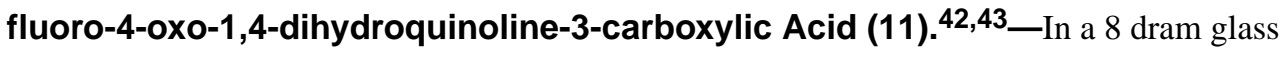
vial, compound $10(0.108 \mathrm{~g}, 0.136 \mathrm{mmol})$ was dissolved in DCM $(700 \mu \mathrm{L})$, and BTMS (686 $\mu \mathrm{L}, 5.20 \mathrm{mmol}$, 38 equiv) was added. The vial was capped and heated overnight at $35^{\circ} \mathrm{C}$ while covered with foil and stirring. The following day, solvent was removed under vacuum, and the crude was quenched with $\mathrm{MeOH}(2 \mathrm{~mL})$. The resulting solution was stirred at room temperature for $30 \mathrm{~min}$. Solvent was removed under vacuum to afford an orange oil. A few drops of water were added to produce a yellow solid. More $\mathrm{MeOH}(2 \mathrm{~mL})$ was added, and the resulting suspension was filtered using a medium-grade fritted glass funnel. The resulting solid was further washed with $\mathrm{MeOH}$ to afford $\mathbf{1 1}$ as a yellow powder $(0.070 \mathrm{~g}$, $82.0 \%$ yield). ${ }^{1} \mathrm{H}$ NMR (400 MHz, deuterium oxide, $\left.\mathrm{pH} 7.5\right): \delta=8.54$ (s, br, $\left.1 \mathrm{H}\right), 7.90-7.87$ (m, 1H), 7.65-7.63 (m,1H), $7.54(\mathrm{~d}, J=8.0,2 \mathrm{H}), 7.44(\mathrm{~d}, J=8.0,2 \mathrm{H}), 4.79$ (m, overlap with $\mathrm{D}_{2} \mathrm{O}, 4 \mathrm{H}$ ), 4.00 (s, br, 2H), 3.79 (s, br, 2H), 3.47 (s, br, 3H), 3.34 (s, br, 2H), 3.21 (td, $J$ $=14.0,6.4,2 \mathrm{H}), 2.30(\mathrm{tt}, J=22.0,6.6,1 \mathrm{H}), 1.38-1.33(\mathrm{~m}, 2 \mathrm{H}), 1.15(\mathrm{~s}, \mathrm{br}, 2 \mathrm{H}) .{ }^{31} \mathrm{P}$ NMR (162 MHz, deuterium oxide, $\mathrm{pH} 7.5) \delta 19.12$. MS (ESI-) $\mathrm{m} / z .622 .24(\mathrm{M}-\mathrm{H})$ calcd for $\mathrm{C}_{26} \mathrm{H}_{27} \mathrm{FN}_{3} \mathrm{O}_{10} \mathrm{P}_{2}^{-}:$622.12. HPLC (Method A, UV 190, 274, $330 \mathrm{~nm}$ ): $t_{\mathrm{r}}=4.43 \mathrm{~min}$. 


\section{Antibacterial Properties of Bisphosphonate-Ciprofloxacin Conjugates}

Experimental Strains-Seven S. aureus clinical osteomyelitis strains of methicillinsusceptible profile and one of methicillin-resistant profile were tested. These pathogens are part of the strain collection of the Department of Pharmaceutical Microbiology and Parasitology Wroclaw Medical University, Poland. Additionally, the following American Type Culture Collection (ATCC) strains were chosen for experimental purposes: $S$. aureus 6538 and $P$. aeruginosa 15442.

HA Discs-For custom disc manufacturing, commercially available HA powder was used. Powder pellets of $9.6 \mathrm{~mm}$ in diameter were pressed without a binder. Sintering was performed at $900{ }^{\circ} \mathrm{C}$. The tablets were compressed using the Universal Testing System for static tensile, compression, and bending tests (Instron model 3384; Instron, Norwood, MA). The quality of the manufactured HA discs was checked by means of confocal microscopy and microcomputed tomography (micro-CT) using an LEXT OLS4000 microscope (Olympus, Center Valley, PA) and Metrotom 1500 microtomograph (Carl Zeiss, Oberkochen, Germany), respectively.

\section{Disc Diffusion Test To Evaluate Sensitivity of Tested Strains to Ciprofloxacin}

-This procedure was performed according to EUCAST guidelines. ${ }^{29}$ Briefly, 0.5 McFarland (MF) of bacterial dilution was spread on Mueller-Hinton (MH) agar plate. The discs containing $5 \mathrm{mg}$ of ciprofloxacin were introduced, and the plate was subjected to incubation at $37^{\circ} \mathrm{C} / 24 \mathrm{~h}$. Next, inhibition zones were recorded using a ruler. Obtained values $(\mathrm{mm})$ were compared to appropriate values of inhibition zones from EUCAST tables. 29

\section{Evaluation of the MIC of Tested Compounds against Planktonic Forms of} Clinical Staphylococcal Strains Analyzed-To assess the impact of parent antibiotic and conjugates on microbial growth, $100 \mu \mathrm{L}$ of microbial solutions of density $1 \times 10^{5}$ $\mathrm{CFU} / \mathrm{mL}$ were placed into wells of 96 -well test plates together with appropriate concentrations of tested compounds. Immediately after that, the absorbance of solutions was measured using a spectrometer (Thermo Scientific Multiscan GO) at $580 \mathrm{~nm}$ wavelength. Subsequently, plates were incubated for $24 \mathrm{~h} / 37^{\circ} \mathrm{C}$ in a shaker to obtain optimal conditions for microbial growth and to prevent bacteria from forming biofilms. After incubation, the absorbance was measured once again. The following control samples were established: negative control sample one: sterile medium without microbes; negative control sample two: sterile medium without microbes implemented with DMSO (Sigma-Aldrich) to final concentration of $1 \%(\mathrm{v} / \mathrm{v})$; positive control sample one: medium + microbes with no compound tested; positive control sample two: medium + microbes with no compound tested but implemented with DMSO to final concentration of $1 \%(\mathrm{v} / \mathrm{v})$. Rationale for use of $1 \%$ DMSO was that ciprofloxacin dissolves efficiently in this solvent, however, concentrations of DMSO $>1 \%$ could be detrimental for microbial cells. To assess relative number of cells, the following calculations were performed. The value of absorbance of control samples (medium + microbes for conjugate, medium + microbes + DMSO for ciprofloxacin) was estimated at $100 \%$. Next, the relative number of cells subjected to 
incubation with tested compounds were counted as follows: value of control sample absorbance/value of tested sample $\times 100 \%$.

To confirm results obtained by spectrophotometric assessments, treated bacterial solutions were transferred to $10 \mathrm{~mL}$ of fresh medium and left for $48 \mathrm{~h}$ at $37^{\circ} \mathrm{C}$. The occurrence of opacification or lack of opacification of media was proof of pathogen growth or lack of growth, respectively. Additionally, bacterial solutions were cultured on the appropriate stable medium. Growth or lack of growth of bacterial colonies together with above-mentioned results from liquid cultures served as confirmation of results obtained spectrophotometrically. Antimicrobial and MIC results for the conjugate here and in upcoming in vitro experiments were calculated based on the amount of the parent antibiotic to allow molar comparison to ciprofloxacin.

\section{Spectroscopic Analysis of 6 and 11 in Tryptic Soy Broth (TSB) Microbiological Media with the Addition of HA Spherules-Various conjugate concentrations were} introduced to HA powder (spherules) suspended in TSB microbiological medium. Solutions containing BP-ciprofloxacin and HA spherules were introduced to wells of a 24-well plate. Final concentration of powder was $10 \mathrm{mg} / 1 \mathrm{~mL}$, while final concentration of conjugates was $0.24-250 \mathrm{mg} / \mathrm{L}$. Immediately afterward, the absorbance of solutions was measured using a spectrometer (Thermo Scientific Multiscan GO) at $275 \mathrm{~nm}$ wavelength. Plates were shaken automatically in the spectrometer prior to assessment. Next, plates were left for $24 \mathrm{~h} / 37^{\circ} \mathrm{C} /$ shaking. After $24 \mathrm{~h}$, absorbance was measured once again. To assess the relative concentration of the conjugate at 0 and $24 \mathrm{~h}$, values of absorbance taken in the beginning and at the end of experiment were compared. The excitation slit, emission slit, integration time, and increment were optimized based on the concentration of samples.

\section{Antimicrobial Susceptibility Testing of 6 against Planktonic Cultures of S.} aureus Strain ATCC-6538 in Acidic versus Physiological pH-This experimental setting was performed in the same manner as described previously for disc diffusion testing, but microbiological media was adjusted to $\mathrm{pH} 7.4$ and $\mathrm{pH} 5$ using $\mathrm{KOH}$ or HCL solution and measured using a universal pH-indicator (Merck, Poland).

Time-Kill Assay for 6 against S. aureus Strain ATCC-6538 (MSSA) and Clinical MRSA Strain (MR4-CIPS)—This experiment was performed in the same manner as described previously in the Evaluation of MIC of Tested Compounds against Planktonic Forms of Clinical Staphylococcal Strains Analyzed section, but absorbance assays (at 580 nm wavelength) were taken in hours $0,1,2,4,8,16$, and 24 .

\section{Antimicrobial Susceptibility Testing of 6 against Preformed Biofilms of S. aureus Strain ATCC-6538 and P. aeruginosa Strain ATCC-15442-Strains cultured on appropriate agar plates (Columbia agar plate for $S$. aureus; MacConkey agar plate for $P$. aeruginosa) were transferred to liquid microbiological media and incubated for $24 \mathrm{~h} / 37^{\circ} \mathrm{C}$ under aerobic conditions. After incubation, strains were diluted to the density of $1 \mathrm{MF}$. The microbial dilutions were introduced to wells of 24-well plates containing HA discs as a substrate or simply to polystyrene wells where the bottom surface of the wells served as the substrate for biofilm development. Strains were incubated at $37^{\circ} \mathrm{C}$ for $4 \mathrm{~h}$. Next, the}


microbe-containing solutions were removed from the wells. The surfaces, HA discs and polystyrene plates, were gently rinsed to leave adhered cells and to remove planktonic or loosely bound microbes. Surfaces prepared in this manner were immersed in fresh TSB medium containing $0.24-125 \mathrm{mg} / \mathrm{L}$ of 6 and ciprofloxacin as a control. After $24 \mathrm{~h}$ of incubation at $37^{\circ} \mathrm{C}$, the surfaces were rinsed using physiological saline solution and transferred to $1 \mathrm{~mL}$ of $0.5 \%$ saponin (Sigma-Aldrich, St Louis, MO). The surfaces were vortex-mixed vigorously for $1 \mathrm{~min}$ to detach cells. Subsequently, all microbial suspensions were diluted $10^{-1}$ to $10^{-9}$ times. Each dilution $(100 \mathrm{~mL})$ was cultured on the appropriate stable medium (MacConkey, Columbia for $P$. aeruginosa and $S$. aureus, respectively) and incubated at $37^{\circ} \mathrm{C}$ for $24 \mathrm{~h}$. After this time, the microbial colonies were counted, and the number of cells forming biofilm was assessed. Results were presented as the mean number of CFU per square millimeter surface \pm standard error of the mean. To calculate the surface area of HA discs, X-ray tomographic analysis was applied. For estimation of the area of test plate bottoms, the equation for circle area: $\pi r^{2}$ was applied.

\section{Preventative Ability of 6 and 11 To Inhibit S. aureus 6538 Adherence to HA-}

Various concentrations of $\mathbf{6}$ and $\mathbf{1 1}$ were introduced to HA powder (spherules) suspended in TSB microbiological medium. Solutions containing 6 and HA spherules were introduced to wells of 24-well plates. Final concentrations of powder were $10 \mathrm{mg} / 1 \mathrm{~mL}$, while final concentrations of the conjugate were $0.12-250 \mathrm{mg} / \mathrm{L}$. Suspensions were left for $24 \mathrm{~h} / 37^{\circ} \mathrm{C} /$ shaking. After $24 \mathrm{~h}$, suspensions were removed from the wells and impulse centrifuged to precipitate HA powder. Next, supernatant was very gently discarded, and a fresh $1 \mathrm{~mL}$ of $S$. aureus of density $10^{5} \mathrm{CFU} / \mathrm{mL}$ was introduced to the HA spherules. Subsequently, this solution was shaken, and absorbance was measured using $580 \mathrm{~nm}$ wavelength and left for 24 $\mathrm{h} / 37^{\circ} \mathrm{C} /$ shaking. After incubation, the absorbance was measured again, and values from 0 and $24 \mathrm{~h}$ were compared to assess reduction of bacterial growth with regard to control sample one (bacterial suspension but no spherules) and control sample two (bacterial suspension + spherules but with no conjugate added). Additionally, solutions were impulse centrifuged, and the supernatant was gently discarded, while bacteria-containing HA spherules were culture plated as before and quantitatively assessed. For testing of 11, solutions containing HA spherules and higher concentrations of $\mathbf{1 1}$ ranging from 1 to 400 $\mu \mathrm{g} / \mathrm{mL}$ and ciprofloxacin concentrations ranging from 0.5 to $400 \mu \mathrm{g} / \mathrm{mL}$ were prepared and again compared to the control sample (bacterial suspension but no HA) for ability to inhibit biofilm formation. Higher concentrations of $\mathbf{1 1}$ were tested because of the demonstrated weaker activity of an amide conjugate as compared to the carbamate conjugate.

\section{Survival of S. aureus after $\mathbf{2 4} \mathrm{h}$ of Incubation on HA Pretreated with 6-HA}

discs were immersed in $2 \mathrm{~mL}$ of solution containing various concentrations of BPciprofloxacin or ciprofloxacin alone and left for $24 \mathrm{~h} / 37^{\circ} \mathrm{C}$. HA discs incubated in DMSO or phosphate buffer served as control samples. Next, discs were rinsed 3 times with sterile water. After rinsing, $2 \mathrm{~mL}$ of $0.5 \mathrm{MF}$ of $S$. aureus ATCC6538 were introduced to wells containing HA discs as a substrate for biofilm development, and biofilms were formed as before. 
Ethics Statement-All animal protocols and procedures were approved and performed in accordance with the Institutional Animal Care and Use Committee (IACUC) of the University of Southern California (USC) and in accordance with the Panel on Euthanasia of the American Veterinary Medical Association. USC is registered with the United States Department of Agriculture (USDA), has a fully approved Letter of Assurance (\#A3518-01) on file with the National Institutes of Health (NIH), and is accredited by the American Association for the Accreditation of Laboratory Animal Care (AAALAC). The title of our IACUC approved protocol is "Bone targeted antimicrobials for biofilm-mediated osteolytic infection treatment", and the protocol number is 20474. All animal protocols, and investigators and staff involved in the animal studies presented herein, adhered to the Guide for the Care and Use of Laboratory Animals, the USDA Animal Welfare Regulations (CFR 1985) and Public Health Service Policy on Humane Care and Use of Laboratory Animals (1996).

In Vivo Animal Study-For this study 12 five-month-old, virgin, female Sprague-Dawley rats weighing approximately $200 \mathrm{~g}$ each were used in this study. Two to three animals were housed per cage in a vivarium at $22{ }^{\circ} \mathrm{C}$ under a $12 \mathrm{~h} \mathrm{light} / 12 \mathrm{~h}$ dark cycle and fed ad libitum with a soft diet (Purina Laboratory Rodent Chow). All animals were treated according to the guidelines and regulations for the use and care of animals at USC. Animals were under the supervision of full-time veterinarians on call $24 \mathrm{~h}$ /day who evaluate the animals personally on a daily basis. All animal experiments are described using the ARRIVE ${ }^{45}$ guidelines for reporting on animal research to ensure the quality, reliability, validity, and reproducibility of results.

This animal model is an in-house jawbone peri-implant osteomyelitis model designed specifically to study biofilm-mediated disease and host response in vivo. ${ }^{31}$ Biofilms of the jawbone osteomyelitis pathogen $A a$ were preformed on miniature titanium implants at $10^{9}$ CFU. To confirm Aa sensitivity to the parent drug ciprofloxacin prior to our animal studies, we performed AST and MIC assays against planktonic $A a$ in addition to the biofilm HA assay as described for the long bone osteomyelitis pathogens. After biofilms were established on the implants in vitro, they were surgically transferred to the jawbone of each rat. For surgery, animals were anesthetized with $4 \%$ isoflurane inhalant initially followed by intraperitoneal injection of ketamine $(80-90 \mathrm{mg} / \mathrm{kg})$ plus xylazine $(5-10 \mathrm{mg} / \mathrm{kg})$. Then local anesthesia was given via infiltration injection of bupivicaine $0.25 \%$ at the surgical site. Buprenorphine sustained release $(1.0-1.2 \mathrm{mg} / \mathrm{kg}$ ) was then given subcutaneously as preemptive analgesia before making initial incisions. Once anesthetized, the buccal mucosa of each rat was retracted, and a transmucosal osteotomy was performed with a pilot drill into the alveolar ridge in the natural diastema of the anterior palate. Implants were then manually inserted into the osteotomy and secured into the bone until the platform is at mucosal level. Two biofilm-inoculated implants were placed in each rat ( $n=12$ rats) in the palatal bone bilaterally.

One week post-operatively, isoflurane $4 \%$ was given again to briefly anesthetize the rats, check implant stability, and document clinical findings at the implant and infection site, such as presence or absence of inflammation. The animals were then dosed via intraperitoneal injection with BP-ciprofloxacin ( 6 at $0.1,1$, or $10 \mathrm{mg} / \mathrm{kg}$ as a single dose and at $0.3 \mathrm{mg} / \mathrm{kg}$ 
$3 \times /$ week for a multiple dosing group) or ciprofloxacin alone $(10 \mathrm{mg} / \mathrm{kg} 3 \times /$ week also as a multiple dosing group) as a positive control, and sterile endotoxin-free saline as a negative control. Allocation of animals to treatment and control groups was done through a randomization process. The multiple dosing group animals were anesthetized as before prior to each additional injection over the course of the week. All compounds were of pharmacological grade and constituted in sterile physiological injectable saline at appropriate $\mathrm{pH}$. One week after pharmacotherapy, all animals were euthanized in a $\mathrm{CO}_{2}$ chamber (60-70\% concentration) for $5 \mathrm{~min}$, followed by cervical dislocation. Resection of peri-implant tissues $\left(1 \mathrm{~cm}^{2}\right)$ was performed en bloc, and implants were removed. Clinical parameters were noted at surgery and resection, such as presence or absence of periprosthetic inflammation. Rat allocations to treatment and control groups were de-identified and concealed from subsequent investigators analyzing the microbial data.

For microbial analysis, resected peri-implant soft tissue and bone was homogenized and processed immediately after surgical resection by placement in $1 \mathrm{~mL}$ of $0.5 \%$ saponine and vortexed for $1 \mathrm{~min}$ before being serially diluted. Serial dilutions at a dilution factor of 10 (e.g., $0.1 \mathrm{~mL}$ of saponine solution transferred to $0.9 \mathrm{~mL}$ of $0.9 \%$ sterile isotonic saline solution) ranging from $10^{0}$ to $10^{-9}$ were prepared, and $0.1 \mathrm{~mL}$ of solution from each of the dilutions was cultured on plates using a spread plate method. The medium for culturing $\mathrm{Aa}$ consisted of modified TSB, and frozen stocks were maintained at $-80{ }^{\circ} \mathrm{C}$ in $20 \%$ glycerol, $80 \%$ modified TSB. All culturing was performed at $37^{\circ} \mathrm{C}$ in $5 \% \mathrm{CO}_{2}$ for $48 \mathrm{~h}$. The numbers of viable Aa bacteria cultured (number of CFUs per gram of tissue) was counted manually, and the reduction in the mean $\log _{10}$ number of CFU per gram as a function of treatment was recorded. In order to confirm Aa bacterial morphotype and also rule out contamination, Gram staining and histologic evaluation were performed by sampling of colonies from plates once CFU counting was completed.

\section{Statistical Analysis}

Statistical calculations were performed with SPSS 22.0 (IBM, Armonk, NY) and Excel 2016 (Microsoft Corporation, Redmond, WA). Power analyses were performed to determine sample size estimation for in vitro and in vivo studies prior to experimentation using $\mathrm{G}$ Power 3 software. ${ }^{46}$ Quantitative data from experimental results for each group were analyzed first with descriptive statistics to understand the distribution of the data (parametric or non-parametric) and to generate the mean, standard error, standard deviation, kurtosis and skewness, and 95\% confidence levels. The data were then analyzed using the KruskallWallis test or one-way ANOVA as applicable, and statistical significance was accepted at $p<$ 0.05 when comparing treatments to controls. Additionally, for in vivo experiments, post-hoc testing using unpaired $t$ tests and Dunnett's test for multiple comparisons was performed.

\section{Supplementary Material}

Refer to Web version on PubMed Central for supplementary material. 


\section{Acknowledgments}

We would like to thank the National Institutes of Health, National Institute of Dental and Craniofacial Research for funding our work (R41-DE025789-01). We would also like to thank Dr. Casey Chen, Dr. Allan Jones, and Dr. Homa Zadeh for their intellectual guidance on various aspects of our study, and Dr. Christoph Schaudinn for his preparation of our SEM image. P.P.S. and F.H.E. received a grant as principal investigators from the National Institutes of Health, National Institute of Dental and Craniofacial Research (\#R41-DE025789-01) for this work, and the funders had no role in study design, data collection and analysis, decision to publish, or preparation of the manuscript.

\section{ABBREVIATIONS USED}

Aa

AAALAC

ANOVA

ARRIVE Animal Research: Reporting of in Vivo Experiments

AST antibiotic sensitivity test

ATCC American Type Culture Collection

BP bisphosphonate

BTMS bromotrimethylsilane

CFU colony-forming units

CLSI Clinical Laboratory Standards Institute

EUCAST European Committee on Antimicrobial Susceptibility Testing

HA hydroxyapatite

IACUC Institutional Animal Care and Use Committee

MBC mean bactericidal concentrations

MBIC $^{50}$ minimal biofilm inhibitory concentration required to inhibit the growth of $50 \%$ of organisms

MF McFarland

MH Mueller-Hinton

MIC $^{50}$ minimal inhibitory concentration required to inhibit the growth of $50 \%$ of organisms

MSSA methicillin-sensitive $S$. aureus

$\mathbf{P d} / \mathbf{C} \quad$ palladium on activated carbon

SD standard deviation

BTMS bromotrimethylsilane 
DCM dichloromethane

$\mathbf{S O C l}_{2} \quad$ thionyl chloride

SEM scanning electron microscopy

\section{References}

1. Lew DP, Waldvogel FA. Osteomyelitis. Lancet. 2004; 364:369-379. [PubMed: 15276398]

2. Desrochers A, St-Jean G, Anderson DE. Limb amputation and prosthesis. Vet. Clin. North. Am. Food Anim. Pract. 2014; 30:143-155. [PubMed: 24534663]

3. Stoodley P, Ehrlich GD, Sedghizadeh PP, Hall-Stoodley L, Baratz ME, Altman DT, Sotereanos NG, Costerton JW, Demeo P. Orthopaedic biofilm infections. Curr. Orthop. Pract. 2011; 22:558-563. [PubMed: 22323927]

4. Huang CC, Tsai KT, Weng SF, Lin HJ, Huang HS, Wang JJ, Guo HR, Hsu CC. Chronic osteomyelitis increases long-term mortality risk in the elderly: a nationwide population-based cohort study. BMC Geriatr. 2016; 16:72. [PubMed: 27029408]

5. Wolcott RD, Ehrlich GD. Biofilms and chronic infections. JAMA. 2008; 299:2682-2684. [PubMed: 18544729]

6. Junka AF, Szymczyk P, Smutnicka D, Kos M, Smolina I, Bartoszewicz M, Chlebus E, Turniak M, Sedghizadeh PP. Microbial biofilms are able to destroy hydroxyapatite in the absence of host immunity in vitro. J. Oral Maxillofac. Surg. 2015; 73:451-464. [PubMed: 25544303]

7. Panagopoulos P, Drosos G, Maltezos E, Papanas N. Local antibiotic delivery systems in diabetic foot osteomyelitis: time for one step beyond? Int. J. Lower Extremity Wounds. 2015; 14:87-91.

8. Puga AM, Rey-Rico A, Magarinos B, Alvarez-Lorenzo C, Concheiro A. Hot melt poly-epsiloncaprolactone/poloxamine implantable matrices for sustained delivery of ciprofloxacin. Acta Biomater. 2012; 8:1507-1518. [PubMed: 22251935]

9. Herczegh P, Buxton TB, McPherson JC 3rd, Kovacs-Kulyassa A, Brewer PD, Sztaricskai F, Stroebel GG, Plowman KM, Farcasiu D, Hartmann JF. Osteoadsorptive bisphosphonate derivatives of fluoroquinolone antibacterials. J. Med. Chem. 2002; 45:2338-2341. [PubMed: 12014972]

10. Buxton TB, Walsh DS, Harvey SB, McPherson JC 3rd, Hartmann JF, Plowman KM. Bisphosphonate-ciprofloxacin bound to Skelite is a prototype for enhancing experimental local antibiotic delivery to injured bone. Br. J. Surg. 2004; 91:1192-1196. [PubMed: 15449273]

11. Kim BN, Kim ES, Oh MD. Oral antibiotic treatment of staphylococcal bone and joint infections in adults. J. Antimicrob. Chemother. 2014; 69:309-322. [PubMed: 24072167]

12. Reeves BD, Young M, Grieco PA, Suci P. Aggregatibacter actinomycetemcomitans biofilm killing by a targeted ciprofloxacin prodrug. Biofouling. 2013; 29:1005-1014. [PubMed: 23952779]

13. Houghton TJ, Tanaka KS, Kang T, Dietrich E, Lafontaine Y, Delorme D, Ferreira SS, Viens F, Arhin FF, Sarmiento I, Lehoux D, Fadhil I, Laquerre K, Liu J, Ostiguy V, Poirier H, Moeck G, Parr TR Jr, Far AR. Linking bisphosphonates to the free amino groups in fluoroquinolones: preparation of osteotropic prodrugs for the prevention of osteomyelitis. J. Med. Chem. 2008; 51:6955-6969. [PubMed: 18834106]

14. Melchior MB, Fink-Gremmels J, Gaastra W. Comparative assessment of the antimicrobial susceptibility of Staphylococcus aureus isolates from bovine mastitis in biofilm versus planktonic culture. J. Vet. Med. Ser. B. 2006; 53:326-332.

15. Amorena B, Gracia E, Monzon M, Leiva J, Oteiza C, Perez M, Alabart JL, Hernandez-Yago J. Antibiotic susceptibility assay for Staphylococcus aureus in biofilms developed in vitro. J. Antimicrob. Chemother. 1999; 44:43-55. [PubMed: 10459809]

16. Ceri H, Olson ME, Stremick C, Read RR, Morck D, Buret A. The Calgary Biofilm Device: new technology for rapid determination of antibiotic susceptibilities of bacterial biofilms. J. Clin. Microbiol. 1999; 37:1771-1776. [PubMed: 10325322]

17. Olson ME, Ceri H, Morck DW, Buret AG, Read RR. Biofilm bacteria: formation and comparative susceptibility to antibiotics. Can. J. Vet. Res. 2002; 66:86-92. [PubMed: 11989739] 
18. Zhang S, Gangal G, Uludag H. 'Magic bullets' for bone diseases: progress in rational design of bone-seeking medicinal agents. Chem. Soc. Rev. 2007; 36:507-531. [PubMed: 17325789]

19. Tanaka KS, Houghton TJ, Kang T, Dietrich E, Delorme D, Ferreira SS, Caron L, Viens F, Arhin FF, Sarmiento I, Lehoux D, Fadhil I, Laquerre K, Liu J, Ostiguy V, Poirier H, Moeck G, Parr TR Jr, Rafai Far A. Bisphosphonated fluoroquinolone esters as osteotropic prodrugs for the prevention of osteomyelitis. Bioorg. Med. Chem. 2008; 16:9217-9229. [PubMed: 18815051]

20. McPherson JC 3rd, Runner R, Buxton TB, Hartmann JF, Farcasiu D, Bereczki I, Roth E, Tollas S, Ostorhazi E, Rozgonyi F, Herczegh P. Synthesis of osteotropic hydroxybisphosphonate derivatives of fluoroquinolone antibacterials. Eur. J. Med. Chem. 2012; 47:615-618. [PubMed: 22093760]

21. Cheong S, Sun S, Kang B, Bezouglaia O, Elashoff D, McKenna CE, Aghaloo TL, Tetradis S. Bisphosphonate uptake in areas of tooth extraction or periapical disease. J. Oral Maxillofac. Surg. 2014; 72:2461-2468. [PubMed: 25262401]

22. Russell RG, Watts NB, Ebetino FH, Rogers MJ. Mechanisms of action of bisphosphonates: similarities and differences and their potential influence on clinical efficacy. Osteoporosis Int. 2008; 19:733-759.

23. Guo X, Shi C, Wang J, Di S, Zhou S. pH-triggered intracellular release from actively targeting polymer micelles. Biomaterials. 2013; 34:4544-4554. [PubMed: 23510854]

24. Ghosh AK, Brindisi M. Organic carbamates in drug design and medicinal chemistry. J. Med. Chem. 2015; 58:2895-2940. [PubMed: 25565044]

25. Ossipov DA. Bisphosphonate-modified biomaterials for drug delivery and bone tissue engineering. Expert Opin. Drug Delivery. 2015; 12:1443-1458.

26. Morioka M, Kamizono A, Takikawa H, Mori A, Ueno H, Kadowaki S, Nakao Y, Kato K, Umezawa K. Design, synthesis, and biological evaluation of novel estradiol-bisphosphonate conjugates as bone-specific estrogens. Bioorg. Med. Chem. 2010; 18:1143-1148. [PubMed: 20071185]

27. Arns S, Gibe R, Moreau A, Monzur Morshed M, Young RN. Design and synthesis of novel bonetargeting dual-action pro-drugs for the treatment and reversal of osteoporosis. Bioorg. Med. Chem. 2012; 20:2131-2140. [PubMed: 22341574]

28. Tanaka KS, Dietrich E, Ciblat S, Metayer C, Arhin FF, Sarmiento I, Moeck G, Parr TR Jr, Far AR. Synthesis and in vitro evaluation of bisphosphonated glycopeptide prodrugs for the treatment of osteomyelitis. Bioorg. Med. Chem. Lett. 2010; 20:1355-1359. [PubMed: 20097069]

29. [accessed January 15, 2017] EUCAST: European Committee on Antimicrobial Susceptibility Testing breakpoint tables for interpretation of MICs and zone diameters. http://www.eucast.org/ clinical_breakpoints/

30. M100-S25 performance standards for antimicrobial susceptibility testing; Twenty-fifth informational supplement. The Clinical and Laboratory Standards Institute; Wayne, PA: 2015.

31. Freire MO, Sedghizadeh PP, Schaudinn C, Gorur A, Downey JS, Choi JH, Chen W, Kook JK, Chen C, Goodman SD, Zadeh HH. Development of an animal model for Aggregatibacter actinomycetemcomitans biofilm-mediated oral osteolytic infection: a preliminary study. J. Periodontol. 2011; 82:778-789. [PubMed: 21222546]

32. Manrique P, Freire MO, Chen C, Zadeh HH, Young M, Suci P. Perturbation of the indigenous rat oral microbiome by ciprofloxacin dosing. Mol. Oral Microbiol. 2013; 28:404-414. [PubMed: 23844936]

33. Oliphant CM, Green GM. Quinolones: a comprehensive review. Am. Fam. Physician. 2002; 65:455-464. [PubMed: 11858629]

34. Redgrave LS, Sutton SB, Webber MA, Piddock LJ. Fluoroquinolone resistance: mechanisms, impact on bacteria, and role in evolutionary success. Trends Microbiol. 2014; 22:438-445. [PubMed: 24842194]

35. Mustaev A, Malik M, Zhao X, Kurepina N, Luan G, Oppegard LM, Hiasa H, Marks KR, Kerns RJ, Berger JM, Drlica K. Fluoroquinolone-gyrase-DNA complexes: two modes of drug binding. J. Biol. Chem. 2014; 289:12300-12312. [PubMed: 24497635]

36. Ayre WN, Birchall JC, Evans SL, Denyer SP. A novel liposomal drug delivery system for PMMA bone cements. J. Biomed. Mater. Res., Part B. 2016; 104:1510-1524. 
37. Nandi SK, Bandyopadhyay S, Das P, Samanta I, Mukherjee P, Roy S, Kundu B. Understanding osteomyelitis and its treatment through local drug delivery system. Biotechnol. Adv. 2016; 34:1305-1317. [PubMed: 27693717]

38. Lin JH. Bisphosphonates: a review of their pharmacokinetic properties. Bone. 1996; 18:75-85. [PubMed: 8833200]

39. Fong IW, Ledbetter WH, Vandenbroucke AC, Simbul M, Rahm V. Ciprofloxacin concentrations in bone and muscle after oral dosing. Antimicrob. Agents Chemother. 1986; 29:405-408. [PubMed: 2940971]

40. Sedghizadeh PP, Jones AC, LaVallee C, Jelliffe RW, Le AD, Lee P, Kiss A, Neely M. Population pharmacokinetic and pharmacodynamic modeling for assessing risk of bisphosphonate-related osteonecrosis of the jaw. Oral Surg. Oral Med. Oral. Pathol. Oral Radiol. 2013; 115:224-232. [PubMed: 23246224]

41. Williams DB, Lawton M. Drying of organic solvents: quantitative evaluation of the efficiency of several desiccants. J. Org. Chem. 2010; 75:8351-8354. [PubMed: 20945830]

42. McKenna CE, Higa MT, Cheung NH, McKenna M-C. The facile dealkylation of phosphonic acid dialkyl esters by bromotrimethylsilane. Tetrahedron Lett. 1977; 18:155-158.

43. McKenna CE, Schmidhuser J. Functional selectivity in phosphonate ester dealkylation with bromotrimethylsilane. J. Chem. Soc., Chem. Commun. 1979:739-739.

44. David T, Kotek J, Kubíček V, Tošner Z, Hermann P, Lukeš I. Bis(phosphonate) -building blocks modified with fluorescent dyes. Heteroat. Chem. 2013; 24:413-425.

45. Kilkenny C, Browne WJ, Cuthi I, Emerson M, Altman DG. Improving bioscience research reporting: the ARRIVE guidelines for reporting animal research. Vet. Clin. Pathol. 2012; 41:2731. [PubMed: 22390425]

46. Faul F, Erdfelder E, Buchner A, Lang AG. Statistical power analyses using G*Power 3.1: tests for correlation and regression analyses. Behav. Res. Methods. 2009; 41:1149-1160. [PubMed: 19897823] 


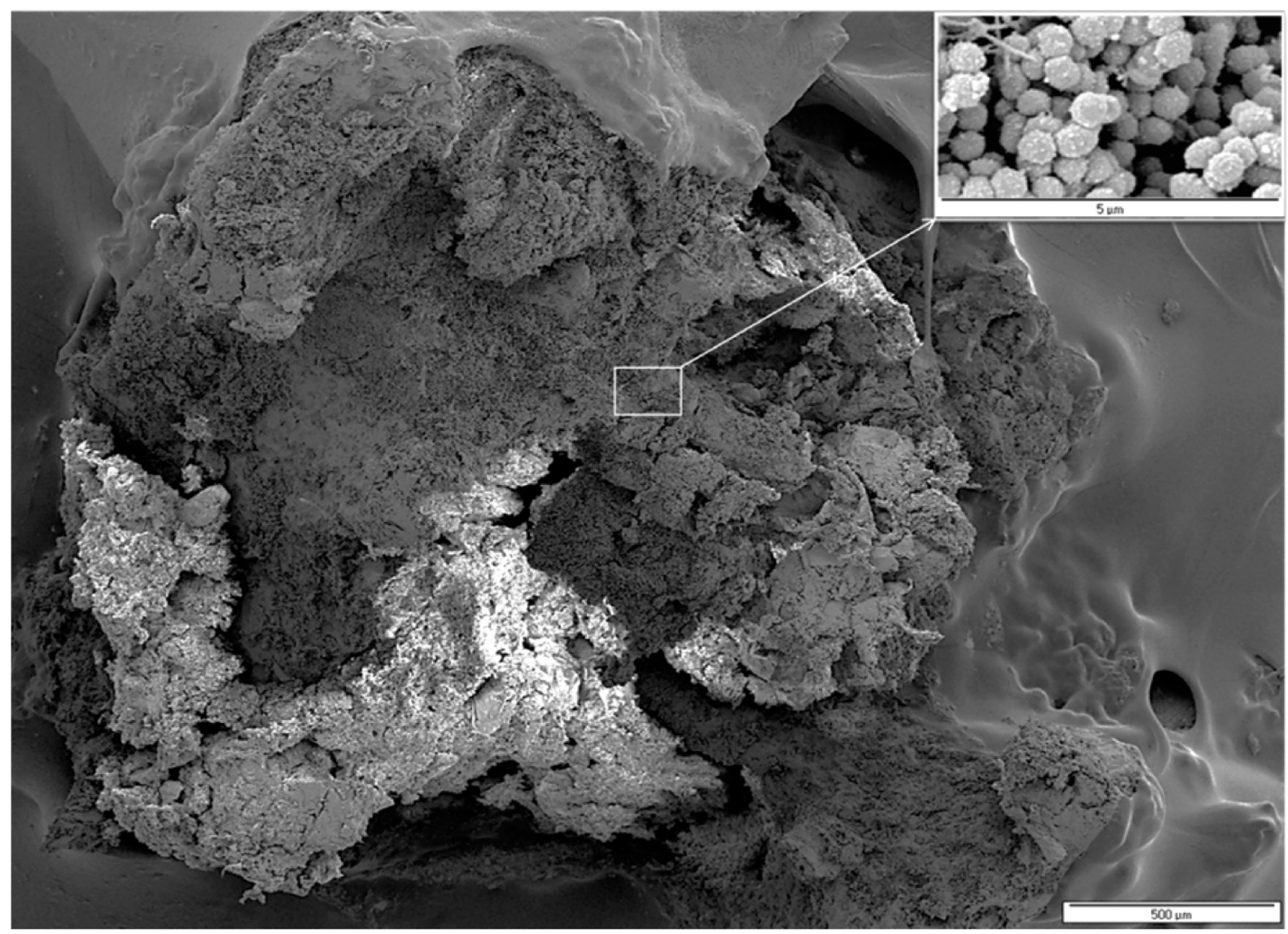

Figure 1.

Scanning electron micrograph of a surgical bone specimen from a patient with chronic osteomyelitis (100× magnification). Characteristic multilayered and matrix-enclosed biofilms colonizing bone surfaces internally and externally can be visualized; inset top right shows high-power view (5000 $\times$ magnification) of the causative staphylococcal biofilm pathogens. [The sample was processed for SEM, sputter coated with platinum, and imaged with an XL 30S SEM (FEG, FEI Co., Hillsboro, OR) operating at $5 \mathrm{kV}$ in the secondary electron mode]. 


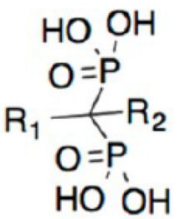

Bisphosphonate

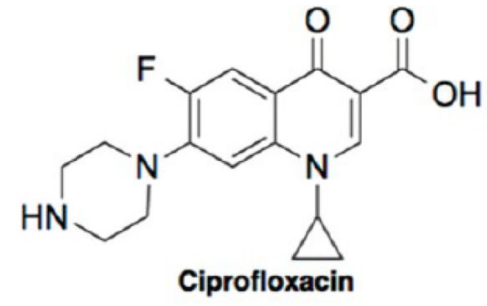

\section{Target \& Release Strategy}
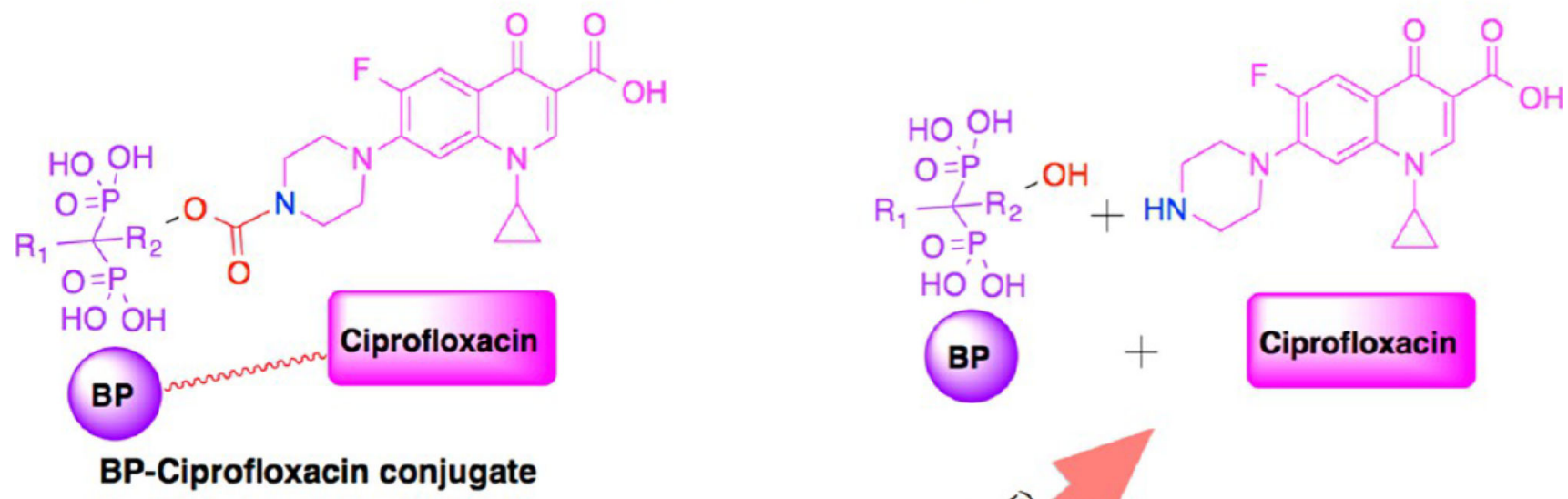

Target to osteolytic infection site

Figure 2.

Design of bisphosphonate-ciprofloxacin conjugate via a "target and release" strategy. 


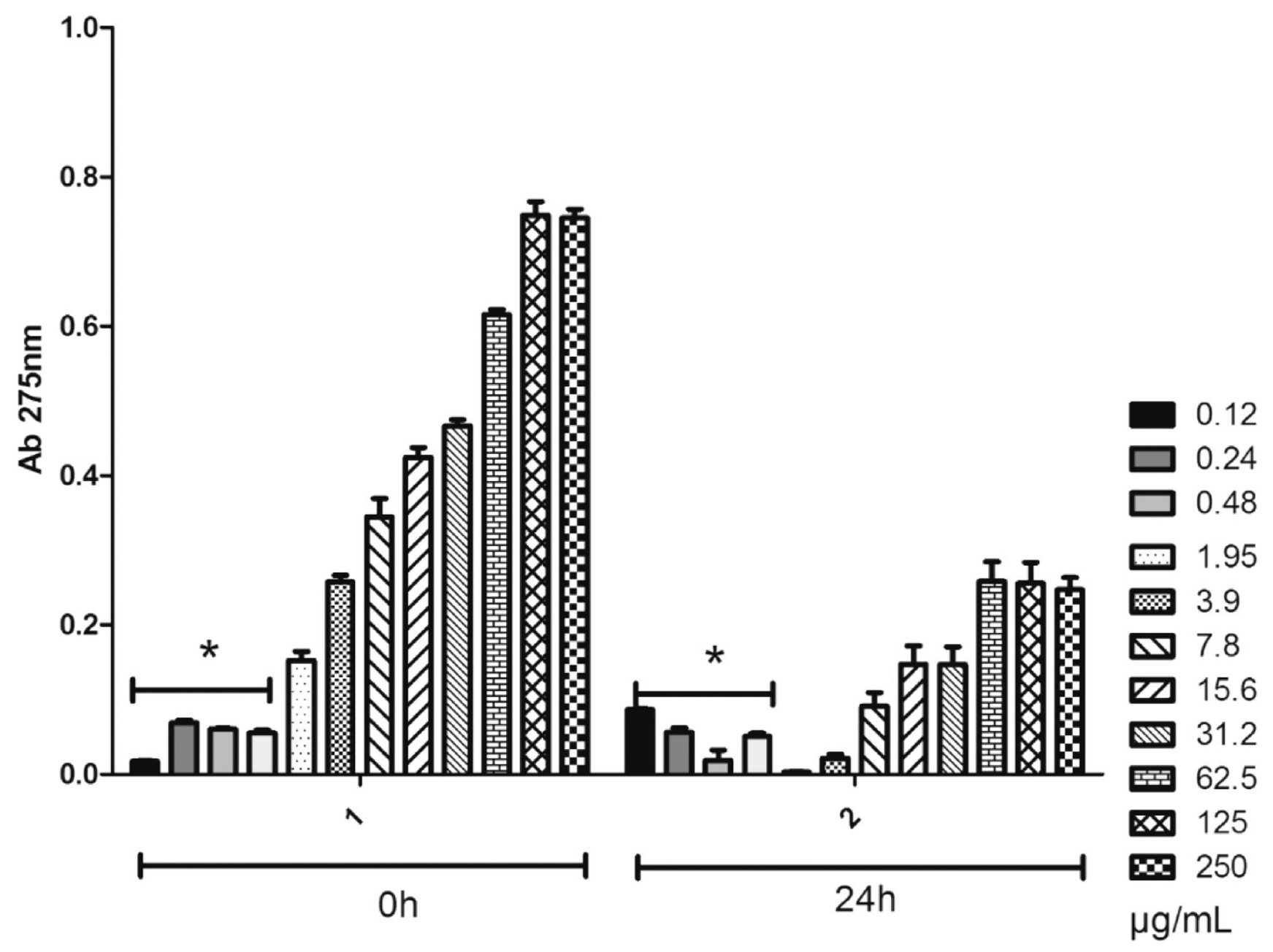

Figure 3.

Spectroscopic analysis of $\mathbf{6}$ in TSB microbiological media with the addition of HA spherules. The significant decreases from 0 to $24 \mathrm{~h}$ confirm conjugate adsorption to HA since the measurement is only performed in the supernatant where the conjugate adsorbed to the HA spherules is absent. [Results for $1.95-250 \mu \mathrm{g} / \mathrm{mL}$ are all statistically significant: $p<$ 0.05 , ANOVA; triplicate; *results for $0.12-0.48 \mu \mathrm{g} / \mathrm{mL}$ (with a horizontal bar above) are inconclusive relative to control medium]. 

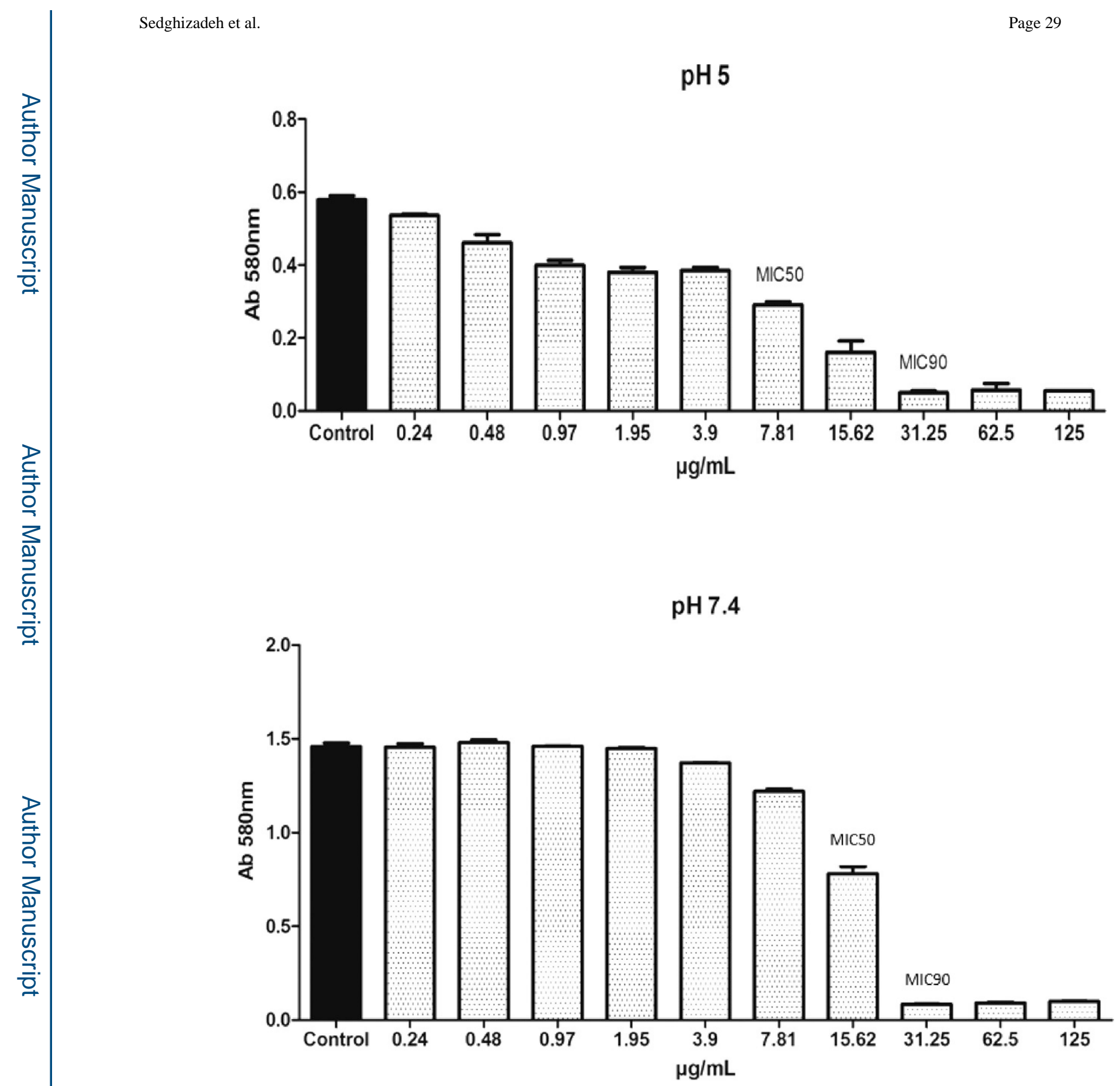

Figure 4.

Antimicrobial susceptibility testing of $\mathbf{6}$ against planktonic cultures of $S$. aureus strain ATCC-6538 in acidic (top graph) and physiological (bottom graph) pH. Results show an improved bactericidal profile in acidic versus physiological $\mathrm{pH}$ as half the concentration of conjugate is required to reach the $\mathrm{MIC}^{50}$ in acidic conditions as compared to physiological conditions. Note that the $\mathrm{MIC}^{90}$ of $31.25 \mu \mathrm{g} / \mathrm{mL}$ in this assay in acidic and physiological conditions is consistent with the MIC results shown in Table 1 for $\mathbf{6}$ against the same strain. 

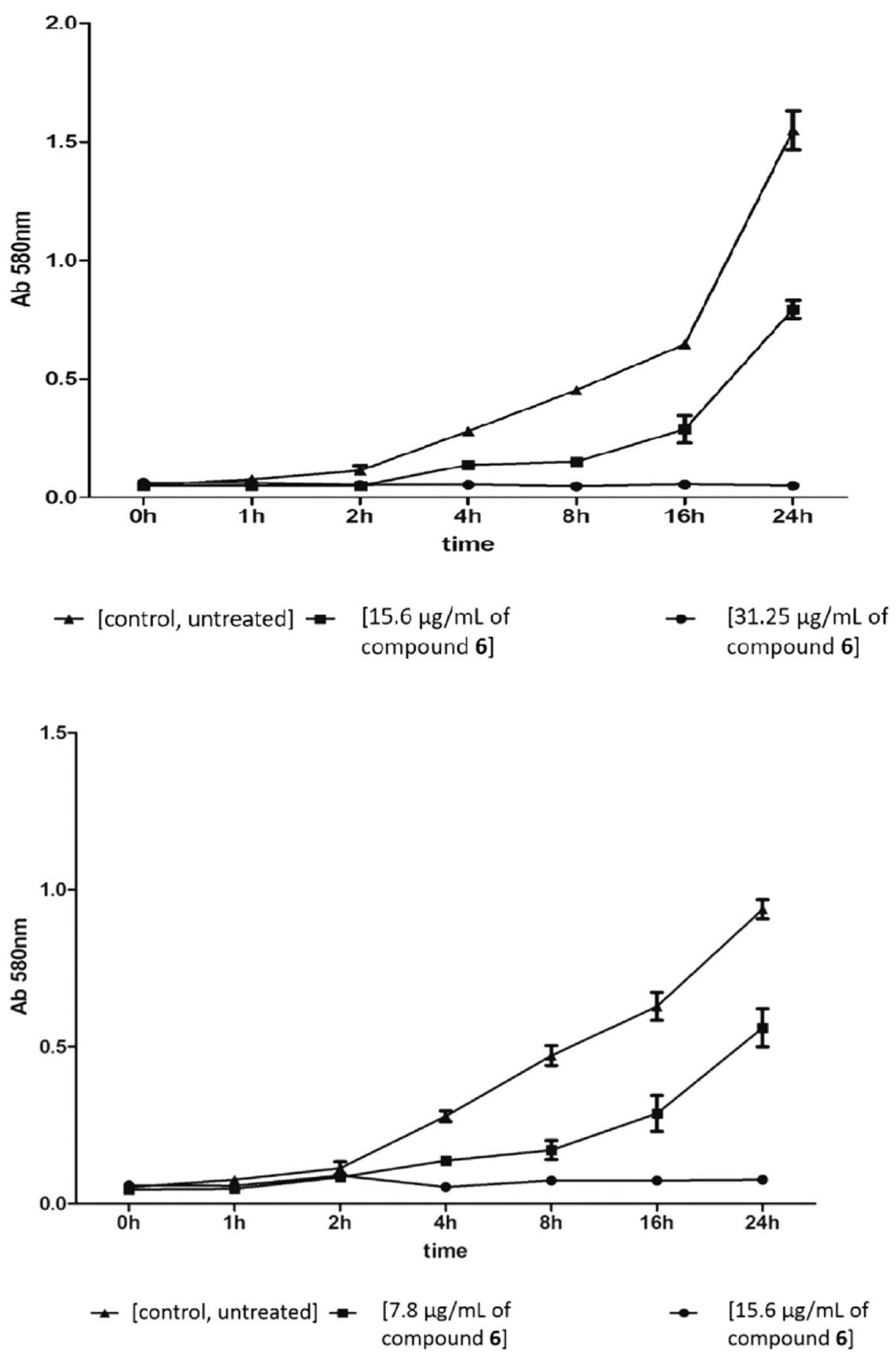

Figure 5.

Time-kill results for 6 against $S$. aureus strain ATCC-6538 (top graph) and MRSA strain MR4-CIPS (bottom graph) at their established MIC values (see Table 1) and at half that value. Kinetic results reveal that at half the MIC value, prevention of bacterial growth became evident after $2 \mathrm{~h}$ and inhibition was at $50 \%$ of control after $24 \mathrm{~h}$. 

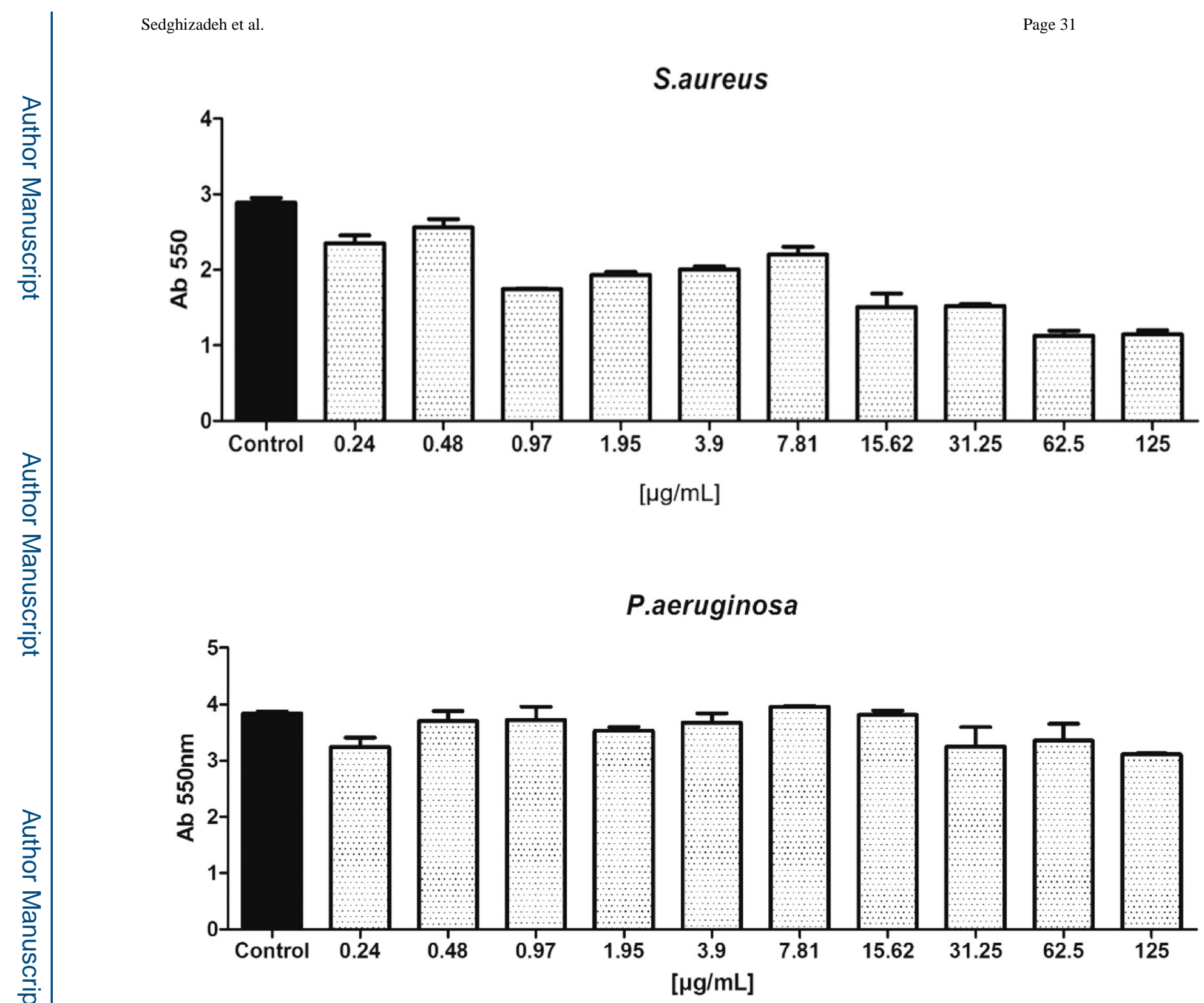

Figure 6.

Antimicrobial susceptibility testing of $\mathbf{6}$ against biofilms of $S$. aureus strain ATCC-6538 (top graph) and $P$. aeruginosa strain ATCC-15442 (bottom graph) formed on polystyrene as a substrate. The conjugate demonstrates minimal activity against biofilms on polystyrene, and no $\mathrm{MBIC}^{90}$ is observed for either pathogen. 


\section{S.aureus}
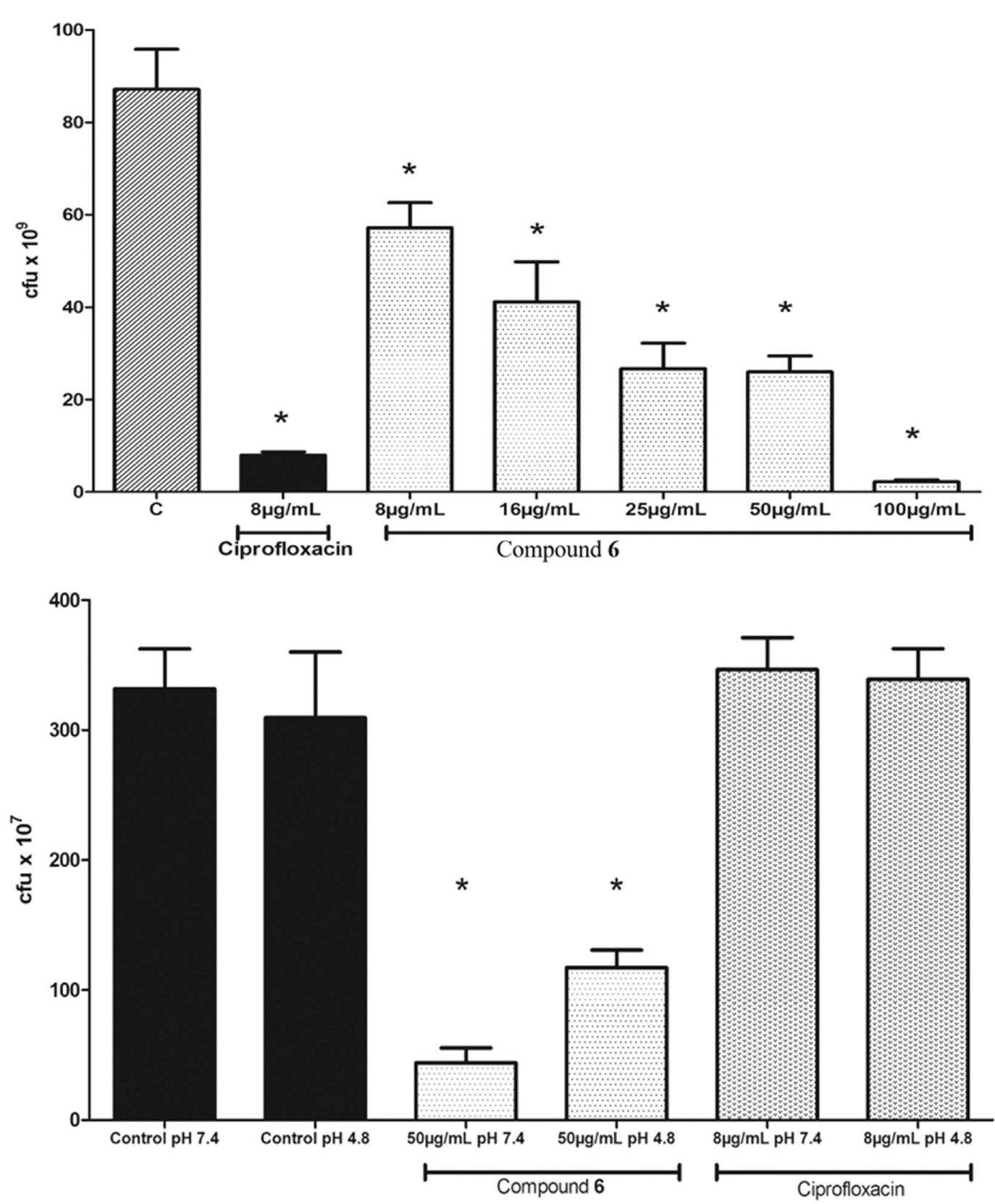

Figure 7.

Antimicrobial susceptibility testing of 6 against biofilms of $S$. aureus strain ATCC-6538 (top graph) and $P$. aeruginosa strain ATCC-15442 (bottom graph) formed on HA discs as the substrate. All tested concentrations of $\mathbf{6}$ (dotted bars top graph) and the parent antibiotic ciprofloxacin resulted in statistically significant bactericidal activity against $S$. aureus; $c=$ negative control comparator. Against $P$. aeruginosa, 6 was most effective at physiological $\mathrm{pH}$ at $50 \mu \mathrm{g} / \mathrm{mL}$ and also effective at acidic $\mathrm{pH}$ at this concentration, but ciprofloxacin was inactive under either acidic or physiological conditions compared to the controls $[* p<0.05$, Kruskal-Wallis test; triplicate]. 


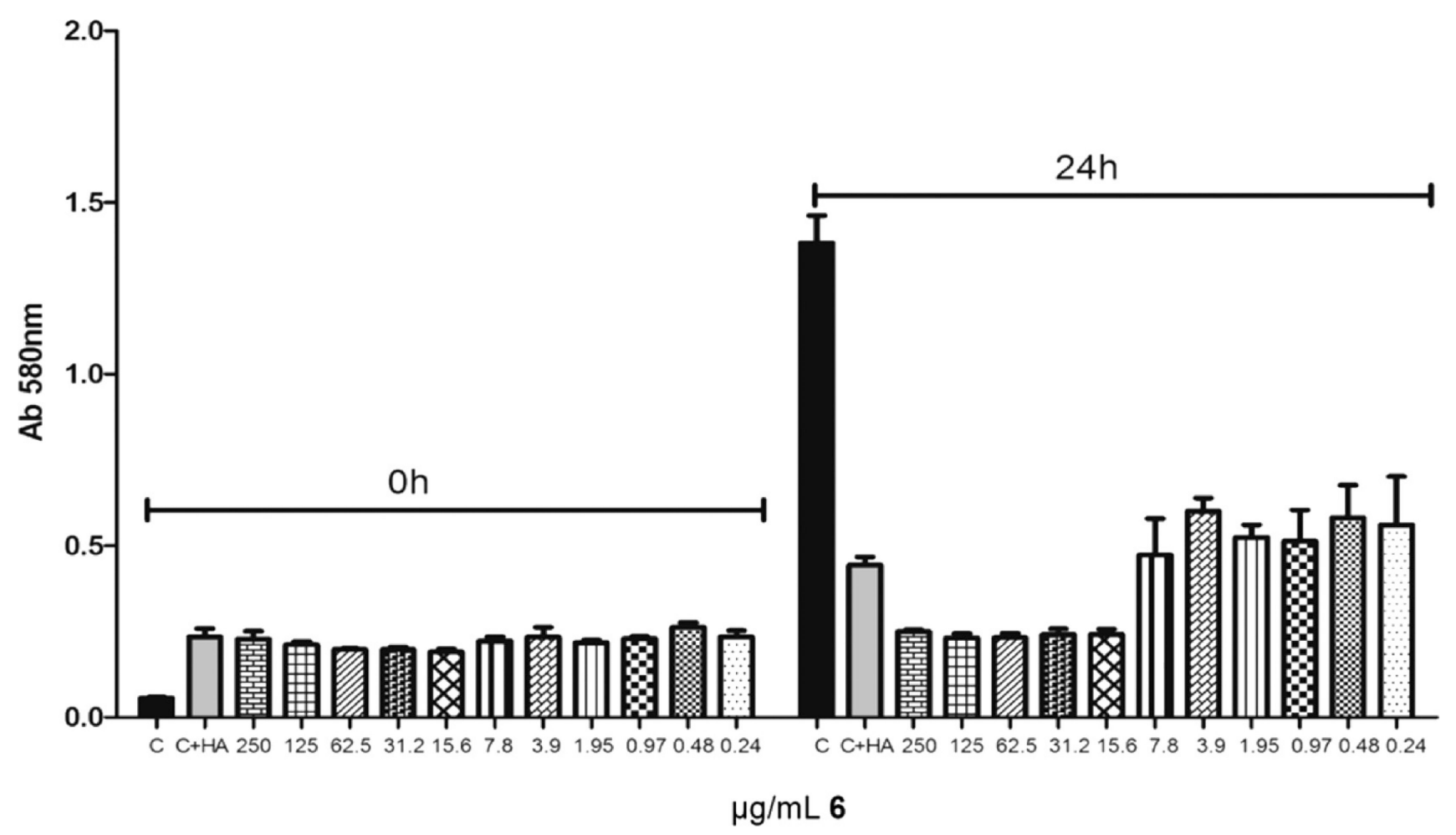

Figure 8.

Results from preventative experiments where HA spherules were pretreated with $\mathbf{6}$ and then inoculated with $S$. aureus. Controls (black bars) represent cultured bacteria without HA and without conjugate treatment. After $24 \mathrm{~h}$, significant increase in planktonic growth is observed when the supernatant is measured. Control + HA $(\mathrm{C}+\mathrm{HA}$ bar) represents cultured bacteria with HA, but still without treatment. After $24 \mathrm{~h}$, some bacterial growth is observed but not as much as in the HA negative control (red bar), because bacteria bind to HA and form biofilms which are not measured in the HA-free supernatant. Comparing controls to treatments, at 15.6 to $250 \mu \mathrm{g} / \mathrm{mL}$ of the conjugate, there is complete bacterial inhibition after $24 \mathrm{~h}$ (right graph); at lower concentrations ranging from 0.24 to $7.8 \mu \mathrm{g} / \mathrm{mL}$, bacteria grew slightly but were still strongly inhibited. 

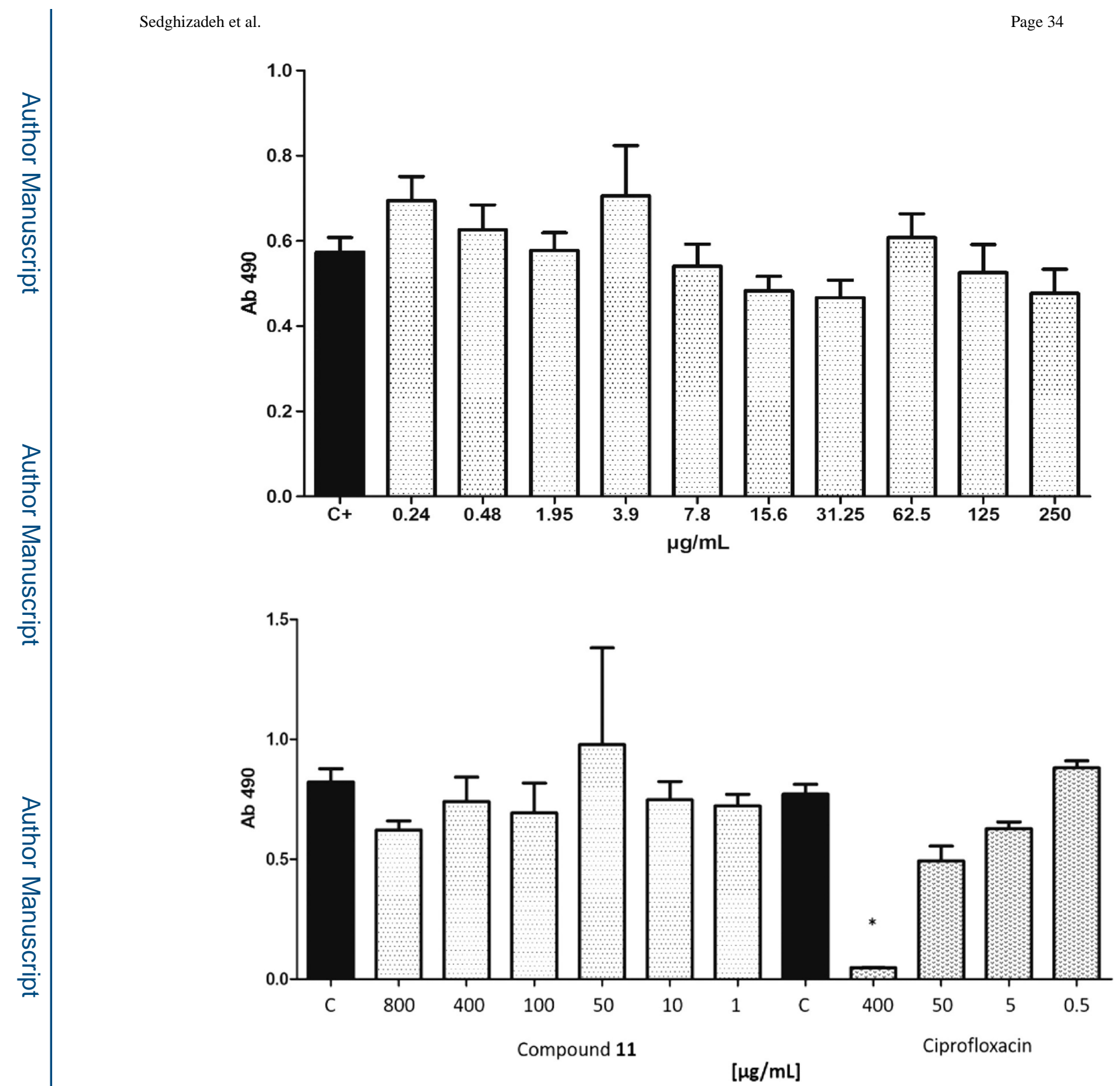

Figure 9.

Antimicrobial susceptibility testing (top graph) of $\mathbf{1 1}$ at increasing concentrations against biofilms of $S$. aureus strain ATCC-6538 formed on HA as the substrate. No significant activity is observed at any concentration as compared to the control $\mathrm{C}+[p>0.05$, KruskalWallis test; triplicate]. The bottom graph shows results from preventative experiments where HA is pretreated with $\mathbf{1 1}$ or the parent antibiotic ciprofloxacin and then inoculated with $S$. aureus, and again no antimicrobial activity is observed for $\mathbf{1 1}$. The only significant reduction is seen with the parent drug at a relatively high dose of $400 \mu \mathrm{g} / \mathrm{mL}\left[{ }^{*} p<0.05\right.$, KruskalWallis test; triplicate]. 


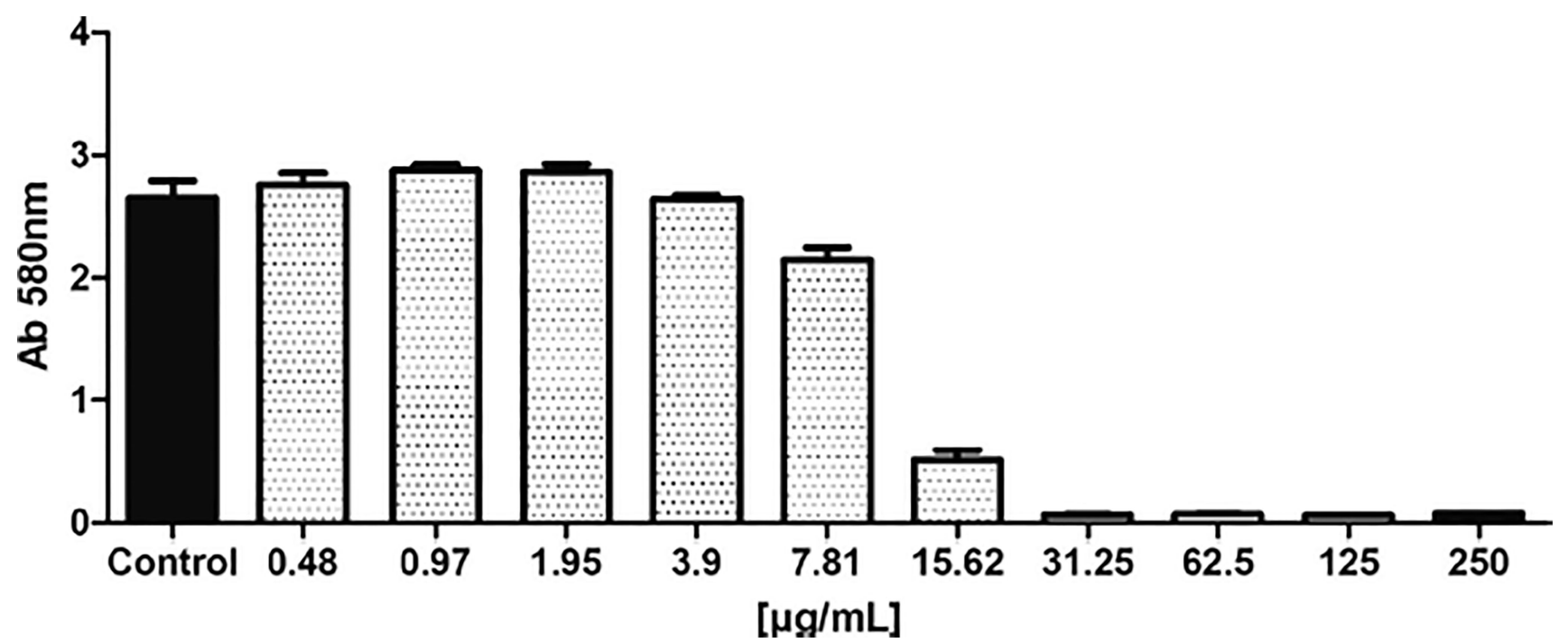

Figure 10.

Antimicrobial susceptibility of 6 against biofilms of $A$ a strain D7S-5 grown on HA shows an effective antimicrobial profile for conjugate 6 at $>15 \mu \mathrm{g} / \mathrm{mL}$. 


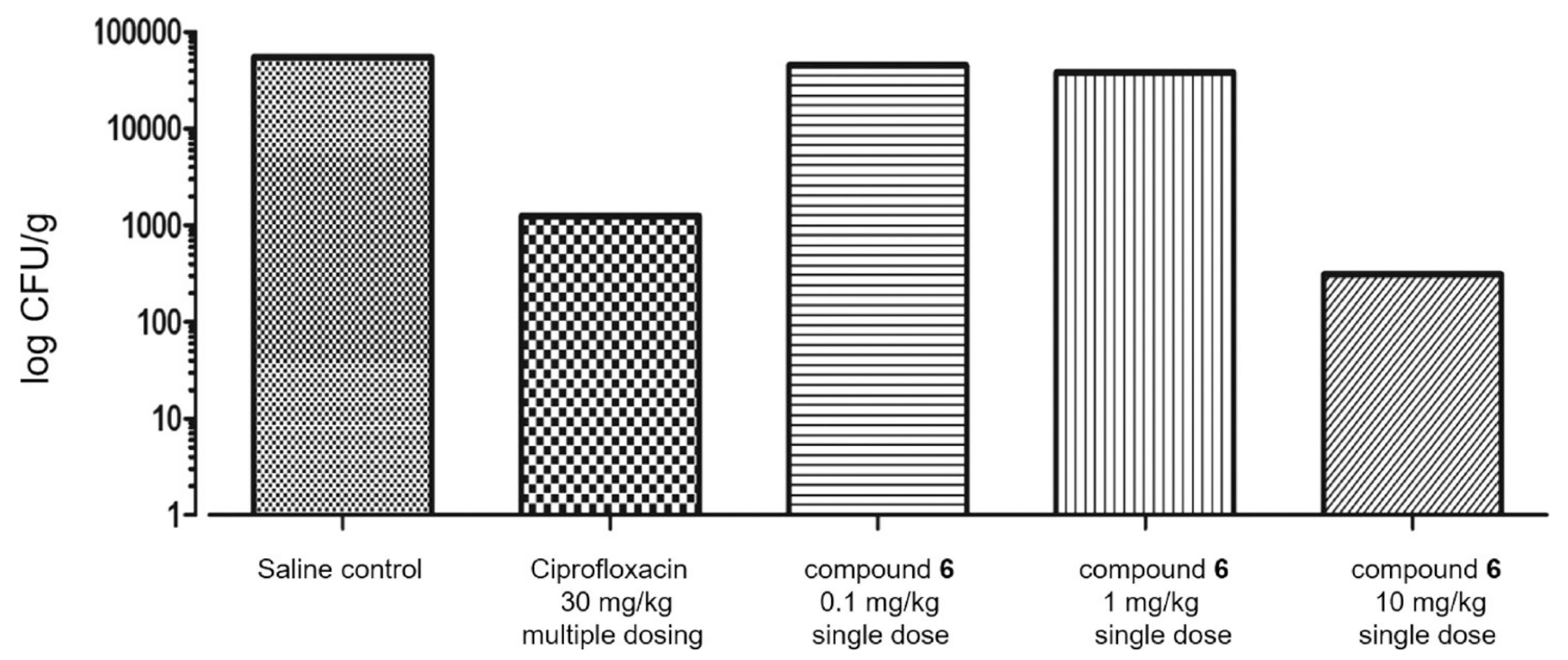

Figure 11.

Antimicrobial results from in vivo animal testing. Data show efficacy of tested compounds for reducing bacterial load. The greatest efficacy was observed at a single high dose (10 $\mathrm{mg} / \mathrm{kg}$ ) of 6 where a $2 \log$ reduction ( $99 \%$ bactericidal activity) was seen as compared to the negative control. 


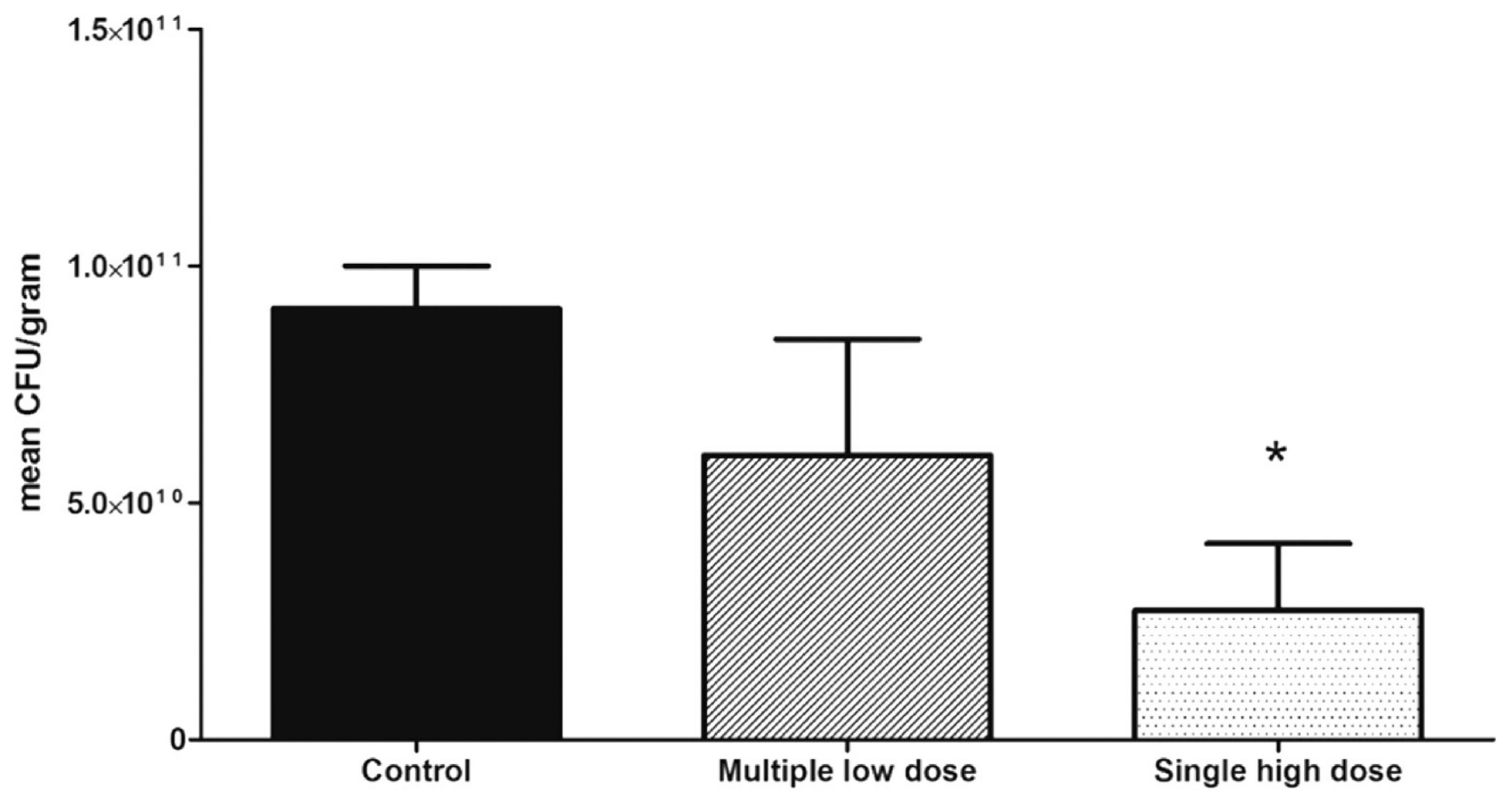

Animal dosing groups

Figure 12.

Antimicrobial results from the second animal experiment. Data show efficacy of $\mathbf{6}$ for reducing bacterial load or mean CFU/gram of tissue ( $y$-axis). The greatest efficacy was observed at a single high dose $(10 \mathrm{mg} / \mathrm{kg})$ of the conjugate compared to the control and the multiple low-dose group $(0.3 \mathrm{mg} / \mathrm{kg} \times 3){ }^{*} p=0.0005$; unpaired $t$ test, errors bars represent standard error]. 
<smiles>CC(C)OP(=O)(OC(C)C)C(Cc1ccc(OCc2ccccc2)cc1)P(=O)(OC(C)C)OC(C)C</smiles><smiles>CC(C)OP(=O)(OC(C)C)C(Cc1ccc(O)cc1)P(=O)(OC(C)C)OC(C)C</smiles><smiles>CC(C)OP(=O)(OC(C)C)C(Cc1ccc(OC(=O)Oc2ccc([N+](=O)[O-])cc2)cc1)P(=O)(OC(C)C)OC(C)C</smiles><smiles></smiles>

Scheme 1. Overall Synthetic Scheme of Aryl Carbamate BP-Ciprofloxacin Conjugate $\boldsymbol{~}^{\boldsymbol{a}}$ ${ }^{a}$ Reagents and conditions: (a) BTMS (2 equiv), $\mathrm{Et}_{2} \mathrm{O}, 0{ }^{\circ} \mathrm{C}$ to rt, $17 \mathrm{~h}$, yield $95 \%$. (b) (i) tetraisopropyl methylene bisphosphonate (1 equiv), $\mathrm{NaH}$ (1 equiv), THF, rt, $10 \mathrm{~min}$; (ii) 1 (1 equiv), rt, $2 \mathrm{~h}$, yield 52\%. (c) $\mathrm{Pd} / \mathrm{C}$ (catalyst) (0.07 equiv), $\mathrm{H}_{2}, \mathrm{MeOH}$, rt, overnight, yield $88 \%$. (d) 4-nitrophenyl chloroformate (1.1 equiv), $\mathrm{Et}_{3} \mathrm{~N}$ ( 3 equiv), DCM, rt, $2.5 \mathrm{~h}$, yield $44 \%$. (e) Ciprofloxacin (1.2 equiv), water ( $\mathrm{pH} 8.5$ ), THF, $0{ }^{\circ} \mathrm{C}$ to rt, overnight, yield 52\%. (f) (i) BTMS (excess), DCM, $35^{\circ} \mathrm{C}, 24 \mathrm{~h}$, (ii) $\mathrm{MeOH}$, rt, overnight, yield $86 \%$. 
<smiles>COC(=O)c1ccc(CC(P(=O)(OC(C)C)OC(C)C)P(=O)(OC(C)C)OC(C)C)cc1</smiles><smiles>CC(C)OP(=O)(OC(C)C)C(Cc1ccc(C(=O)Cl)cc1)P(=O)(OC(C)C)OC(C)C</smiles><smiles>CC(C)OCOC(C)C</smiles>

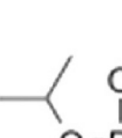<smiles>CCC(C)C</smiles><smiles>C1CCCC1</smiles>

9

10<smiles>CC(C)(C)O[13C](C)(C)C(C)(C)C</smiles>

Scheme 2. Overall Synthetic Scheme of Amide BP-Ciprofloxacin Conjugate $11^{b}$

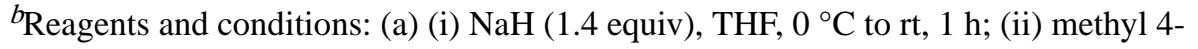
(bromomethyl)benzoate ( 0.7 equiv), THF, $0{ }^{\circ} \mathrm{C}$ to rt, overnight, yield $37 \%$. (b) $\mathrm{LiOH} \cdot \mathrm{H}_{2} \mathrm{O}$ (5 equiv), $\mathrm{MeOH}$, rt, overnight, yield $91 \%$. (c) $\mathrm{SOCl}_{2}$ ( 2 equiv), DMF (0.05 equiv), DCM, rt, 2 $\mathrm{h}$, yield quantitative. (d) Ciprofloxacin (1 equiv), DIPEA (6 equiv), $\mathrm{CHCl}_{3}$, rt, overnight, yield $65 \%$. (e) (i) BTMS (excess), DCM, $35{ }^{\circ} \mathrm{C}$, overnight, (ii) $\mathrm{MeOH}, \mathrm{rt}, 30 \mathrm{~min}$, yield $82 \%$. 


\section{Table 1}

Antimicrobial Susceptibility Testing Results for Ciprofloxacin, 6, and 11 Tested against a Panel of Clinically Relevant $S$. aureus Osteomyelitis Pathogens ${ }^{a}$

\begin{tabular}{lclrr}
\hline & $\begin{array}{c}\text { antibiotic } \\
\text { sensitivity (S) } \\
\text { or resistance } \\
(\mathbf{R})\end{array}$ & $\begin{array}{l}\text { MIC for } \\
\text { ciprofloxacin } \\
{[\boldsymbol{\mu g} / \mathbf{m L}]}\end{array}$ & $\begin{array}{r}\text { MIC } \\
\text { for 6 } \\
{[\boldsymbol{\mu g} /]} \\
\mathbf{m L}]\end{array}$ & $\begin{array}{r}\text { MIC for 11 } \\
{[\boldsymbol{\mu} \mathbf{g} / \mathbf{m L}]}\end{array}$ \\
\hline MSSA1 & $\mathrm{S}$ & 1 & 3.9 & 31.2 \\
MSSA2 & $\mathrm{S}$ & 0.25 & 0.49 & 31.2 \\
MSSA3 & $\mathrm{S}$ & 0.25 & 0.49 & 15.6 \\
MSSA4 & $\mathrm{S}$ & 1 & 3.9 & 62.5 \\
MSSA5 & $\mathrm{S}$ & 0.5 & 1.9 & 7.8 \\
MSSA6 & $\mathrm{S}$ & 1 & 7.8 & 15.6 \\
MSSA:ATCC-6538 & $\mathrm{S}$ & 1 & 31.2 & 62.5 \\
MRSA:MR4-CIPS & $\mathrm{S}$ & 1 & 15.6 & Not tested \\
\hline
\end{tabular}

${ }^{a}$ MSSA = methicillin-susceptible $S$. aureus; MRSA = methicillin-resistant $S$. aureus. 


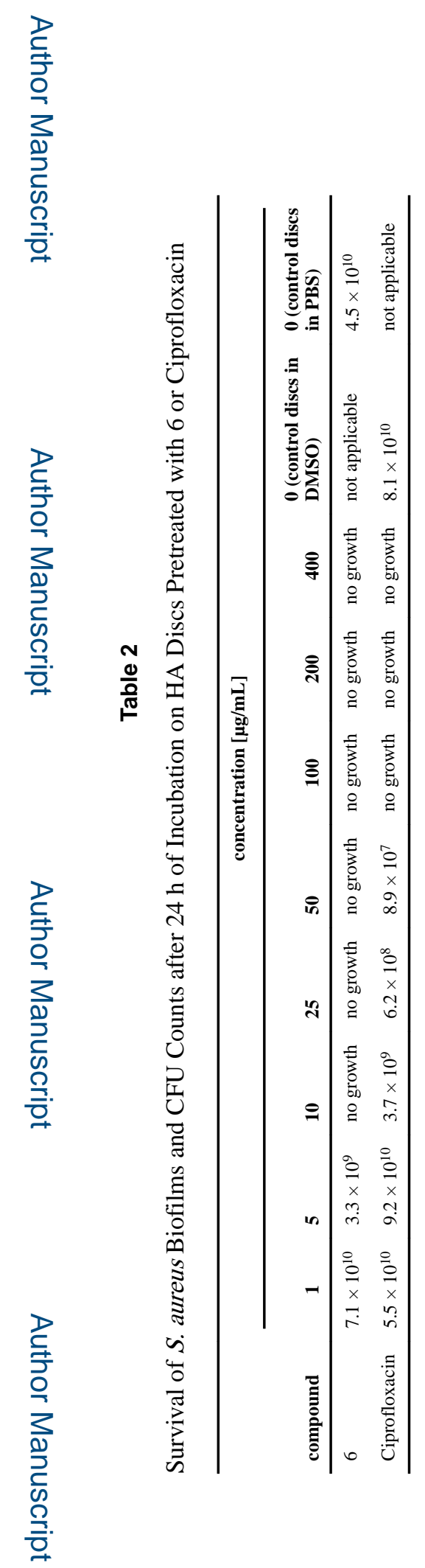

J Med Chem. Author manuscript; available in PMC 2018 March 23. 